\title{
Interactions between human immunodeficiency virus (HIV)-1 Vpr expression and innate immunity influence neurovirulence
}

Hong Na', Shaona Acharjee ${ }^{1}$, Gareth Jones ${ }^{4}$, Pornpun Vivithanaporn ${ }^{1,5}$, Farshid Noorbakhsh' ${ }^{1}$ Nicola McFarlane ${ }^{2}$, Ferdinand Maingat ${ }^{1}$, Klaus Ballanyi ${ }^{3}$, Carlos A Pardo ${ }^{6}$, Éric A Cohen ${ }^{7}$ and Christopher Power ${ }^{1,2,4^{*}}$

\begin{abstract}
Background: Viral diversity and abundance are defining properties of human immunodeficiency virus (HIV)-1's biology and pathogenicity. Despite the increasing availability of antiretroviral therapy, HIV-associated dementia (HAD) continues to be a devastating consequence of HIV-1 infection of the brain although the underlying disease mechanisms remain uncertain. Herein, molecular diversity within the HIV-1 non-structural gene, Vpr, was examined in RNA sequences derived from brain and blood of HIV/AIDS patients with or without HIV-associated dementia (HAD) together with the ensuing pathobiological effects.

Results: Cloned brain- and blood-derived full length vpr alleles revealed that amino acid residue 77 within the brain-derived alleles distinguished HAD (77Q) from non-demented (ND) HIV/AIDS patients (77R) $(p<0.05)$ although vpr transcripts were more frequently detected in HAD brains $(p<0.05)$. Full length HIV-1 clones encoding the 77RND residue induced higher IFN- $\alpha, M X 1$ and BST-2 transcript levels in human glia relative to the 77Q-HAD encoding virus $(p<0.05)$ but both viruses exhibited similar levels of gene expression and replication. Myeloid cells transfected with 77Q-(pVpr77Q-HAD), 77R (pVpr77R-ND) or Vpr null (pVpr $\left.r^{(-)}\right)$-containing vectors showed that the pVpr77R-ND vector induced higher levels of immune gene expression $(p<0.05)$ and increased neurotoxicity $(p<$ 0.05). Vpr peptides (amino acids 70-96) containing the 77Q-HAD or 77R-ND motifs induced similar levels of cytosolic calcium activation when exposed to human neurons. Human glia exposed to the 77R-ND peptide activated higher transcript levels of IFN- $\alpha, M X 1$, PRKRA and BST-2 relative to 77Q-HAD peptide $(p<0.05)$. The Vpr 77R-ND peptide was also more neurotoxic in a concentration-dependent manner when exposed to human neurons $(p<0.05)$. Stereotaxic implantation of full length Vpr, 77Q-HAD or 77R-ND peptides into the basal ganglia of mice revealed that full length Vpr and the 77R-ND peptide caused greater neurobehavioral deficits and neuronal injury compared with 77Q-HAD peptide-implanted animals $(p<0.05)$.
\end{abstract}

Conclusions: These observations underscored the potent neuropathogenic properties of $\mathrm{Vpr}$ but also indicated viral diversity modulates innate neuroimmunity and neurodegeneration.

\section{Background}

Human immunodeficiency virus type 1 (HIV-1) infection is a global health problem for which the pathogenic mechanisms causing disease occurrence and the acquired immunodeficiency syndrome (AIDS) are incompletely understood [1-5]. HIV infection of the brain is a major component of HIV-associated disease

\footnotetext{
* Correspondence: chris.power@ualberta.ca

'Department of Medicine University of Alberta, Edmonton, AB, T6G 2S2, Canada

Full list of author information is available at the end of the article
}

burden because of the brain's comparatively privileged sites for viral replication and persistence; moreover, the brain is relatively inaccessible to many antiretroviral therapies [6-8]. HIV-associated dementia (HAD) is caused by infection of the brain with ensuing glial activation and neuronal damage and death, characterized by motor, behavioral, and progressive cognitive dysfunction [9]. The prevalence of HAD is approximately $5-10 \%$ in antiretroviral therapy-exposed populations. HAD arises due to both pathogenic host responses, mediated by infected and activated microglia and astrocytes, as well

\section{() Biomed Central}


as the cytotoxic properties of viral proteins in susceptible individuals [10-14]. Among the expressed viral proteins, viral protein $\mathrm{R}(\mathrm{Vpr})$ has garnered increasing attention because of its importance in terms of modulating HIV infection of macrophages, regulation of cell cycle pathways and its pro-apoptotic actions [15-19]. Vpr causes neuronal apoptosis through disruption of mitochondrial function [20-22].

Molecular diversity is one of HIV's defining properties, which has precluded the development of effective antiHIV vaccines but also contributes to the emergence of both virulent and drug-resistant viral strains [23-25]. Among blood-derived HIV sequences, Vpr exhibits molecular diversity although the mechanistic consequences of these sequence differences are unclear but appear to be associated with clinical phenotypes in some circumstances [26-29]. Given these circumstances including $\mathrm{Vpr}$ expression and potential pathogenic actions in the brain together with its capacity to mutate in conjunction with clinical phenotypes, it was hypothesized that Vpr might show molecular diversity in the brain, influencing its functions as a neurotoxic ligand or a pathogenic modulator of neuroinflammation [30-32]. Herein, brain-derived HIV-1 Vpr sequences exhibited a consistent mutation, which distinguished non-demented (ND) from demented (HAD) HIV/AIDS patients; the molecular motif within $\mathrm{Vpr}$ associated with dementia was less neuropathogenic but also exerted blunted antiviral and neurotoxic host responses, providing a new perspective into HIV-associated neurovirulence.

\section{Results}

\section{HIV-1 vpr sequence diversity in brain and blood}

Previous studies indicated both Vpr-encoding transcripts and proteins were present in the brains of HIV-infected persons [20,33], chiefly in cells of monocytoid lineage in keeping with other studies of HIV neurotropism [34,35]. To extend these analyses, full length $v p r$ sequences were amplified from subcortical frontal white matter and PBMCs from HAD and ND patients. Alignment of the predicted amino acid sequences showed that there was substantial heterogeneity throughout the brain-derived sequences among both HAD and ND patients using the HIV-1 JR-CSF Vpr sequence as a reference. However, at amino acid residue 77 , there was a significant sequence dichotomy in that a glutamate (Q) predominated in HAD clones (17/18) but at the same position, an arginine (R) was chiefly present in ND clones (7/9) (Figure 1A). To verify this observation, we analyzed bloodderived sequences from HAD and ND AIDS patients, which showed molecular diversity at multiple positions in both the HAD and ND groups but the amino acid changes distinguishing HAD and ND in brain were not evident (Figure 1B). The nature of the molecular diversity in $v p r$ was investigated further by examining the diversity of synonymous mutations within clinical groups, which did not differ within blood- or brainderived sequences from each group (Figure $1 \mathrm{C}$ ). The frequencies of non-synonymous mutations was significantly lower within the HAD brain-derived sequences compared with the HAD blood-derived sequences (Figure 1D). Conversely, the $\mathrm{dN} / \mathrm{dS}$ rates did not differ among blood- and brain-derived sequences (Figure 1E). Complementing the observation of a lower non-synonymous rate in HAD brain-versus blood-derived sequences, the numbers of amino acid differences were also significantly lower in the HAD brain-derived sequences than in HAD blood-derived sequences (data not shown). However, the frequency of detection of $v p r$ transcripts in brain was significantly higher among HAD patients (59\%) compared with ND patients (31\%) (Figure $1 \mathrm{~F})$. In contrast, $v p r$ transcripts were detected in all blood-derived samples examined, regardless of clinical diagnosis. These observations highlighted a distinct mutation which distinguished HAD from ND brainderived $v p r$ sequences together with greater rates of $v p r$ transcript detection in HAD brains.

\section{Intracellular actions of Vpr 77R and 770}

Diversity at amino acid position 77 has been previously recognized in blood-derived samples from HIV/AIDS although the associated effects of this mutation in the nervous system were uncertain $[27,29,36]$. To determine the actions of each amino acid at position 77 on immune activation and the consequent effects on neuronal viability, the full length $v p r$ allele was cloned and thereafter mutated at position 77, generating 77Q( $\mathrm{p} V p r 77 Q-H A D)$ or 77R ( $\mathrm{p} V p r 77 R-N D)$-containing vectors. To ensure expression of the $\mathrm{Vpr}$ protein, $\mathrm{Vpr}$ immunoreactivity was analyzed following transfection of cultured CrFK cells with 77R- or 77Q-containing vpr vectors, together with a non-expressing vector $\left(\mathrm{p} V p r^{(-)}\right)$ and mock transfection (Figure 2). In the non-expressing vector $\left(\mathrm{p} V p r^{(-)}\right)$, the $V p r$ start codon "ATG" was substituted to "ACG". As expected, Vpr immunoreactivity was not detectable in the mock (Figure 2A) and was minimally detectable in the $\mathrm{p} V p r^{(-)}$-transfected cells (Figure 2B) [37]. However, Vpr immunoreactivity was abundant in the cytoplasm and nuclei of cells transfected with the $\mathrm{p} V p r 77 R-N D$ (Figure 2C) and $\mathrm{p} V p r 77 Q-H A D$ (Figure $2 \mathrm{D})$ vectors, confirming the expression of $\mathrm{Vpr}$ by $77 \mathrm{R}$ and $77 \mathrm{Q}$ vectors.

$\mathrm{Vpr}$ has been reported to exert both immune and cytotoxic effects depending on the model [20,25,38-41]. To assess the effects of each vpr-containing vector, immune gene expression was measured in electroporation-transfected myeloid (U937) cells, which revealed that $\mathrm{p} V p r 77 R-N D$ induced $T N F-\alpha$ significantly more 


\section{A}

JR-CSF
12B-HAD-BR
12B-1-HAD-Br
12B-2-HAD-Br
12B-3-HAD-Br
$18 \mathrm{E}-\mathrm{HAD}-\mathrm{Br}$
$18 \mathrm{E}-5-\mathrm{HAD}-\mathrm{Br}$
$18 \mathrm{E}-7-\mathrm{HAD}-\mathrm{Br}$
$18 \mathrm{E}-8-\mathrm{HAD}-\mathrm{Br}$
$18 \mathrm{E}-9-\mathrm{HAD}-\mathrm{Br}$
$28 \mathrm{E}-\mathrm{HAD}-\mathrm{Br}$
$28 \mathrm{E}-8-\mathrm{HAD}-\mathrm{Br}$
$28 \mathrm{E}-10-\mathrm{HAD}-\mathrm{Br}$
$28 \mathrm{~F}-\mathrm{HAD}-\mathrm{Br}$
$362-\mathrm{HAD}-\mathrm{Br}$
$476-\mathrm{HAD}-\mathrm{Br}$
$506-\mathrm{HAD}-\mathrm{Br}$
$527-\mathrm{HAD}-\mathrm{Br}$
$547-\mathrm{HAD}-\mathrm{Br}$
13C-ND-Br
13C-4-ND-Br
$26 \mathrm{D}-\mathrm{ND}-\mathrm{Br}$
$26 \mathrm{D}-2-\mathrm{ND}-\mathrm{Br}$
$26 \mathrm{D}-5-\mathrm{ND}-\mathrm{Br}$
$26 \mathrm{D}-7-\mathrm{ND}-\mathrm{Br}$
$277-\mathrm{ND}-\mathrm{Br}$
$489-\mathrm{ND}-\mathrm{Br}$
$491-\mathrm{ND}-\mathrm{Br}$

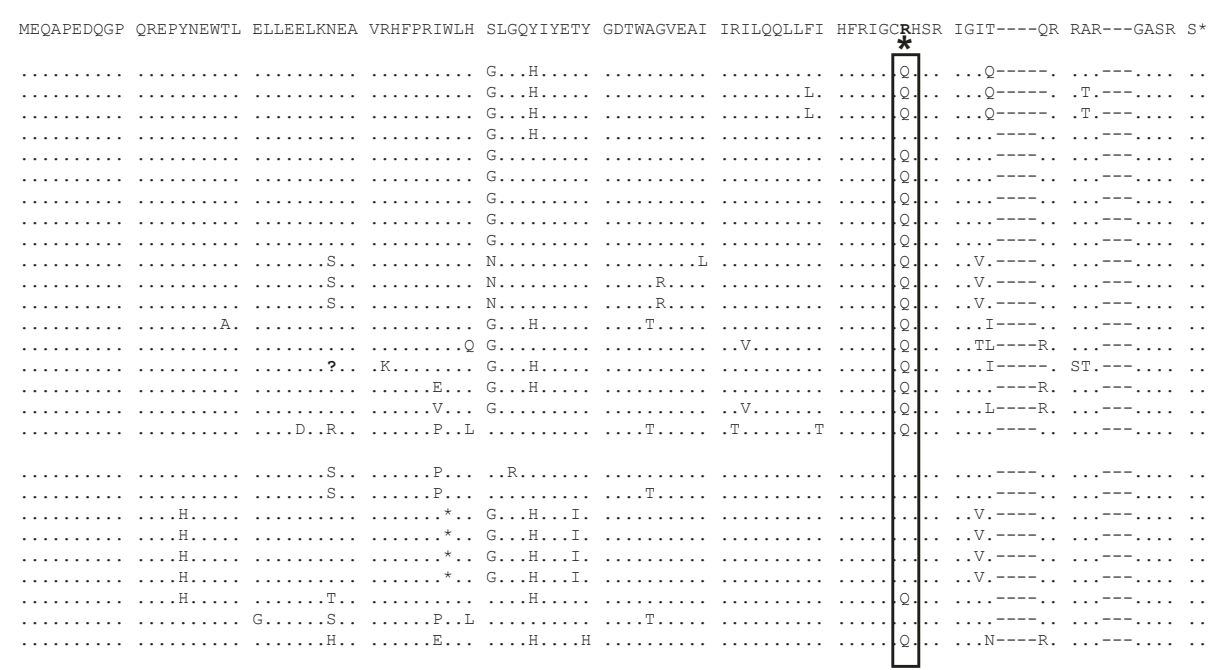

B

JR-CSF

MEQAPEDQGP QREPYNEWTL ELLEELKNEA VRHFPRIWLH SLGQYIYETY GDTWAGVEAI IRILQQLLFI HFRIGCRHSR IGIT-----QR RAR---GASR S*

002-HAD-BI

$004-\mathrm{HAD}-\mathrm{BI}$

$005-\mathrm{HAD}-\mathrm{B} 1$

010-HAD-B1

017-HAD-BI

018-HAD-BI

021-HAD-BI

021-HAD-BI

022-HAD-BI

028-HAD-BI

031-HAD-B

006-ND-B1

007-ND-BI

007-ND-B1

009-ND-BI

011-ND-BI

012-ND-B1

013-ND-B1

014-ND-B1

015-ND-B1

023-ND-B1
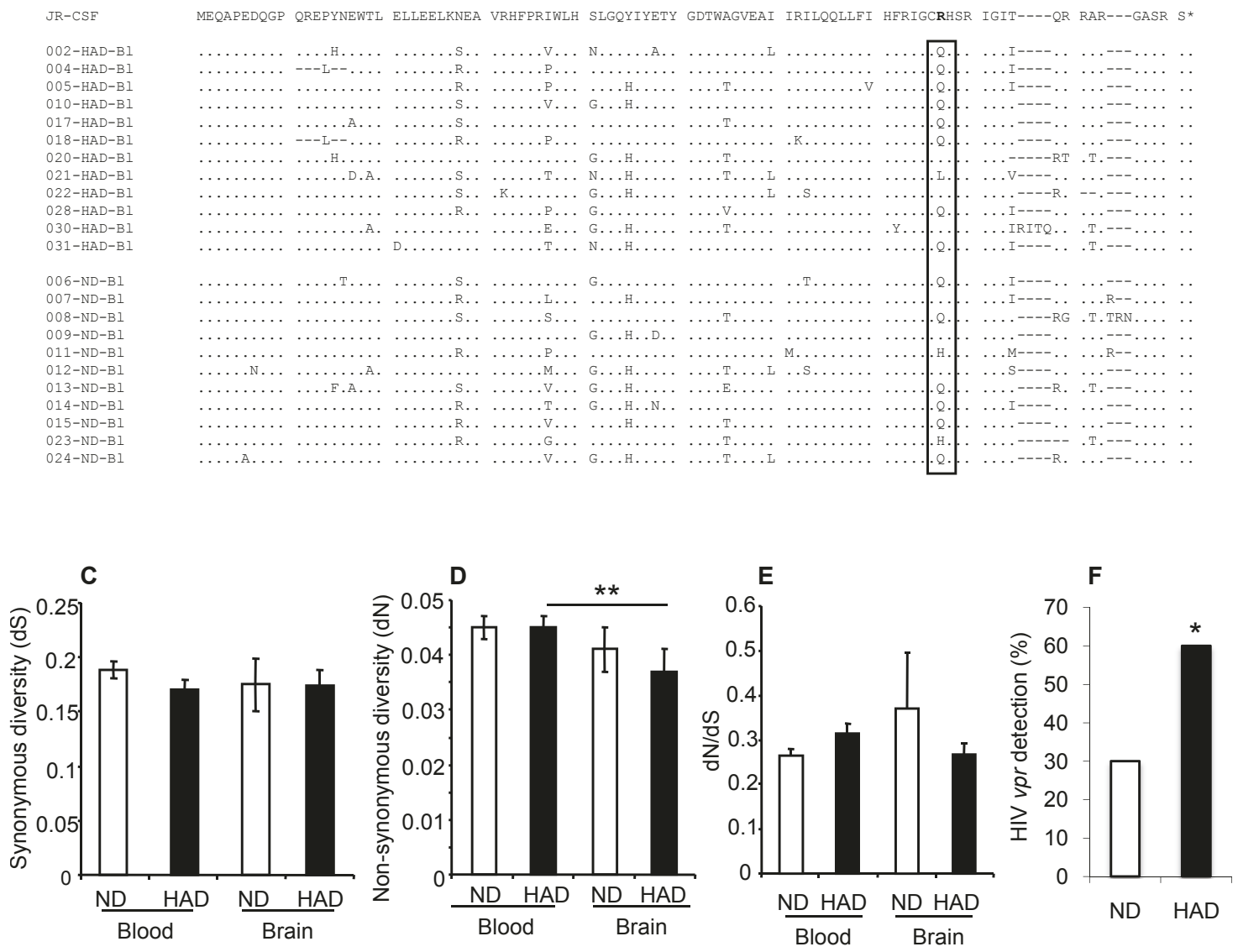

Figure 1 Brain- and blood-derived Vpr sequences. (A) Brain-derived sequences exhibited diversity in both the HAD and ND groups but a mutation at position 77 significantly distinguished the clinical groups with a Q predominating in the HAD group and an R being most evident in the ND group. (B) Blood-derived sequences also demonstrated molecular heterogeneity in both groups but there were no residues that distinguished the clinical groups. (C) The frequency of within-groups synonymous mutations was similar among all sequences from all clinical groups. (D) The frequency of within-group non-synonymous mutations was lower in the brain-derived HAD sequences compared with the blood-derived HAD sequences. (E) Conversely, the ratios of within-group non-synonymous to synonymous mutations did not differ within the clinical groups. (F) The frequency of detecting vpr sequences in brain was significantly higher in the HAD group compared with the ND groups (A, B, F: Mann-Whitney U test; C-D: ANOVA, Bonferroni post hoc test; $\left.{ }^{*} p<0.05\right)$. 

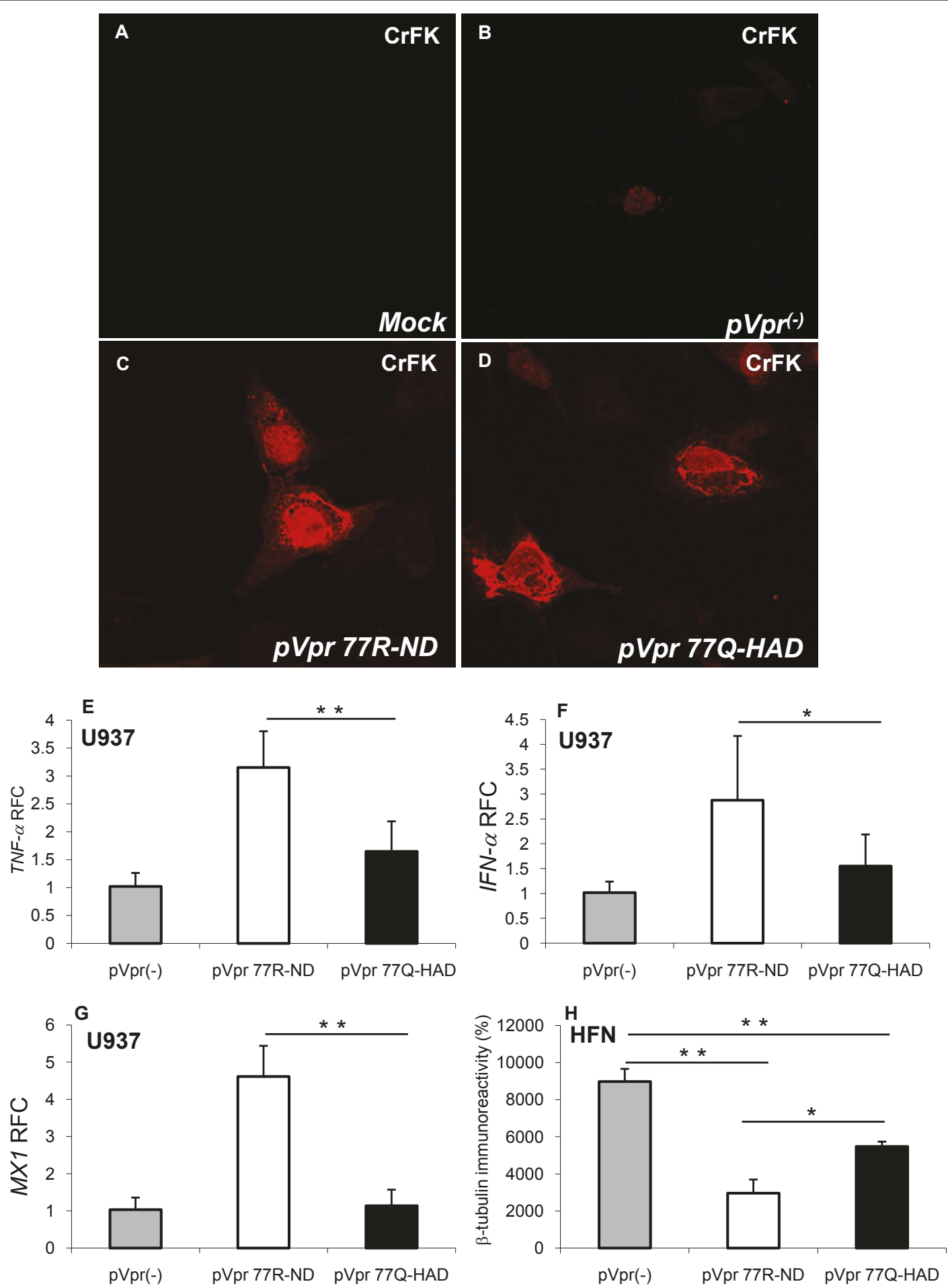

Figure 2 Expression and intracellular actions of Vpr $\mathbf{7 7 Q}$ and 77R. (A) Mock-transfected CrFK cells exhibited no Vpr immunoreactivity; (B) A non-expressing Vpr plasmid $\left(\mathrm{pVpr} r^{(-)}\right.$) also show weakly Vpr immunoreactivity in transfected CrFK cells; (C) and (D) Vpr immunoreactivity was readily detected in the cytoplasm and nuclei of CrFK cells transfected with (C) pVpr77R-ND and (D) pVpr77Q-HAD; (E) pVpr77R-ND transfection of U937 cells caused an induction of TNF- $\alpha / V p r$ transcript abundance relative to $\mathrm{pVpr} r^{(-)}$; (F) likewise, pVpr77R-ND activated IFN- $\alpha / V p r$ transcription in U937 cells; (G) pVpr77R-ND also induced expression of MX1/vpr; (H) Supernatants from both pVpr77Q-HAD and pVpr77R-ND transfected U937 cells were neurotoxic to human fetal neurons (HFN), as evidenced by reduced $\beta$-tubulin immunoreactivity, although the supernatants from the pVpr77R-ND transfected U937 cells were more cytotoxic. Original magnification 600x. Real time PCR data was normalized against the matched Vpr mRNA levels. Experiments were carried out in triplicate at least two times (E-G, Dunnett test, relative to control; ${ }^{*} p<0.05,{ }^{* *} p<0.01$ ). 
than $\mathrm{p} V p r 77 \mathrm{Q}-H A D$ and $\mathrm{p} V p r^{(-)}$(Figure 2E). Likewise, $\mathrm{p} V p r 77 R-N D$ also significantly activated $I F N-\alpha$ (Figure 2F) and $M X 1$ (Figure 2G) transcriptional activity in monocytoid cells. These studies were extended by assessing the neurotoxic effects of supernatants from transfected cells applied to human fetal neurons (Figure $2 \mathrm{H}$ ), which demonstrated that supernatants derived from $\mathrm{p}$ Vpr77R-ND- and $\mathrm{p}$ Vpr77Q-HAD-transfected myeloid cells caused significant reductions in neuronal viability, measured by $\beta$-tubulin immunoreactivity in human fetal neurons compared with supernatants from the $\mathrm{p} V p r$ $(-)$-transfected cells. However, the supernatants from the $\mathrm{p}$ Vpr77R-ND-transfected myeloid cells were significantly more neurotoxic in this assay. These studies highlighted Vpr's capacity to induce variable neuroimmune responses, depending on the individual $\mathrm{Vpr}$ allele but also underlined an association between immune response and related neurotoxicity with the supernatants from $\mathrm{p} V p r 77 R-N D$-transfected cells showing the greatest neurotoxicity.

\section{Transduction of glial cells with viruses expressing Vpr mutants}

In addition to studying the actions of $\mathrm{Vpr}$ in isolation, its effects were examined in the context of whole virus expression in which viruses encoding $\mathrm{Vpr} 77 \mathrm{R}, 77 \mathrm{Q}$ or null were constructed. All of the viruses induced IFN- $\alpha$ expression following transduction of human astrocytes, although there was least IFN- $\alpha$ activation in the $\mathrm{Vpr}$ $77 \mathrm{Q}-$ encoding virus-transfected cells (Figure 3A). Likewise, all virus-transduced astrocytes displayed induction of $M X 1$ (Figure 3B) and BST-2 (Figure 3C) but again lowest levels were observed in the Vpr 77Q-encoding virus-transduced cells for both host genes. Conversely, all of the virus-transduced cells exhibited reduced PRKRA expression relative to the mock-transduced astrocytes (Figure 3D). HIV-1 pol mRNA levels were detected in all transduced cells but were highest in cells transfected with the Vpr 77Q-encoding virus (Figure $3 \mathrm{E}$ ), which was complemented by a similar profile in RT activity in matched supernatants (Figure 3F). These findings suggested an inverse relationship between viral gene expression and specific host immune responses, depending on both the presence and sequence of $\mathrm{Vpr}$.

Vpr peptides (aa 70-96) activate neuronal calcium fluxes While Vpr is expressed within cells as part of viral transport to the nucleus as well as viral assembly [42-45], it is also secreted into cerebrospinal fluid and plasma and acts at the neuronal membrane to influence neuronal function and survival $[22,46]$. It has been previously shown that a C-terminal domain of the Vpr protein (amino acids 70-96) has a critical role in Vprmediated cytotoxic effects [47]. Given that the R77Q mutation was located within this domain of the protein, we investigated the effects of the amino acid 77 mutation using 70-96 Vpr peptides, containing either Vpr77Q ( $\Delta$ Vpr77Q-HAD) or Vpr77R ( $\Delta$ Vpr77R-ND). Previous reports indicate that $\mathrm{Vpr}$ is capable of reducing neuronal viability by inducing apoptosis as well as perturbing the cell cycle machinery [20,47-49]. However, its effects on intracellular calcium fluxes in neurons are less certain. Vpr peptides' actions on neuronal cytosolic calcium mobilization were assessed by confocal microscopy in Fluor-4 prior-loaded human neurons. Glutamate $(500 \mu \mathrm{M})$, which was used a positive control, activated robust responses in terms of changes in intracellular calcium concentrations $\left[\mathrm{Ca}^{2+}\right]_{\mathrm{i}}$ (Figure $4 \mathrm{~A}$ ) but in addition, both $\triangle \mathrm{Vpr} 77 \mathrm{R}-\mathrm{ND}(\mathrm{n}=30)$ and $\triangle \mathrm{Vpr} 77 \mathrm{Q}-$ $\operatorname{HAD}(5.0 \mu \mathrm{M})(\mathrm{n}=19)$ also activated calcium responses in human neurons. The temporal profiles of $\mathrm{Vpr}$ peptides' actions were similar to glutamate, albeit at lower signal amplitudes (Figure 4B-E). This observation was confirmed by graphic analysis, which showed that the Vpr peptides caused smaller changes in $\left[\mathrm{Ca}^{2+}\right]_{\mathrm{i}}$, compared with glutamate exposure to neurons (Figure $4 \mathrm{E}$ ). Thus, in contrast to the assays described above, amino acids $\mathrm{Q}$ or $\mathrm{R}$ at position 77 within Vpr modulated calcium responses similarly in neurons.

\section{Mutant Vpr peptides (aa 70-96) show differential effects on host immune responses}

Since microglia and astrocytes represent the principal innate immune cells within the brain, the actions of soluble $\mathrm{Vpr}$ on their function were highly relevant to the present experiments. Human fetal microglia (HF $\mu \Phi)$ were exposed to $\mathrm{Vpr}$ peptides revealing that the $\triangle$ Vpr77R-ND peptide activated greater IFN- $\alpha$ (Figure 5A), MX1 (Figure 5B), PRKRA (Figure 5C) and BST-2 (Figure 5D) expression compared with $\triangle \mathrm{Vpr} 77 \mathrm{Q}-$ HAD- or mock-exposed microglia. Likewise, human fetal astrocytes (HFA) exposed to the $\Delta$ Vpr77R-ND peptide displayed the highest induction of IFN- $\alpha$ (Figure 5E), MX1 (Figure 5F) and PRKRA (Figure 5G). Both $\triangle \mathrm{Vpr}$ peptides did not activate expression of $I L$ $1 \beta$ or TNF- $\alpha$ in both primary human cell types (data not shown). $\Delta \mathrm{Vpr}$ peptides were also applied to human fetal neurons (HFN) showing $\Delta$ Vpr77R-ND $(30.0 \mu \mathrm{M})$ was neurotoxic while $\Delta \mathrm{Vpr} 77 \mathrm{Q}-\mathrm{HAD}(30.0 \mu \mathrm{M})$ did not differ from the mock-exposed cultures (Figure $5 \mathrm{H}$ ). Both $\Delta$ Vpr77R-ND and $\Delta$ Vpr77Q-HAD $(60.0 \mu \mathrm{M})$ significantly reduced $\beta$-tubulin immunoreactivity but again $\triangle$ Vpr77R-ND was more neurotoxic at this concentration. Of note, the full length (amino acids 1-96) Vpr $(1.0 \mu \mathrm{M})$ was substantially more neurotoxic than both Vpr peptides, emphasizing the importance of the full length Vpr molecule for mediating Vpr's neurovirulent properties. 


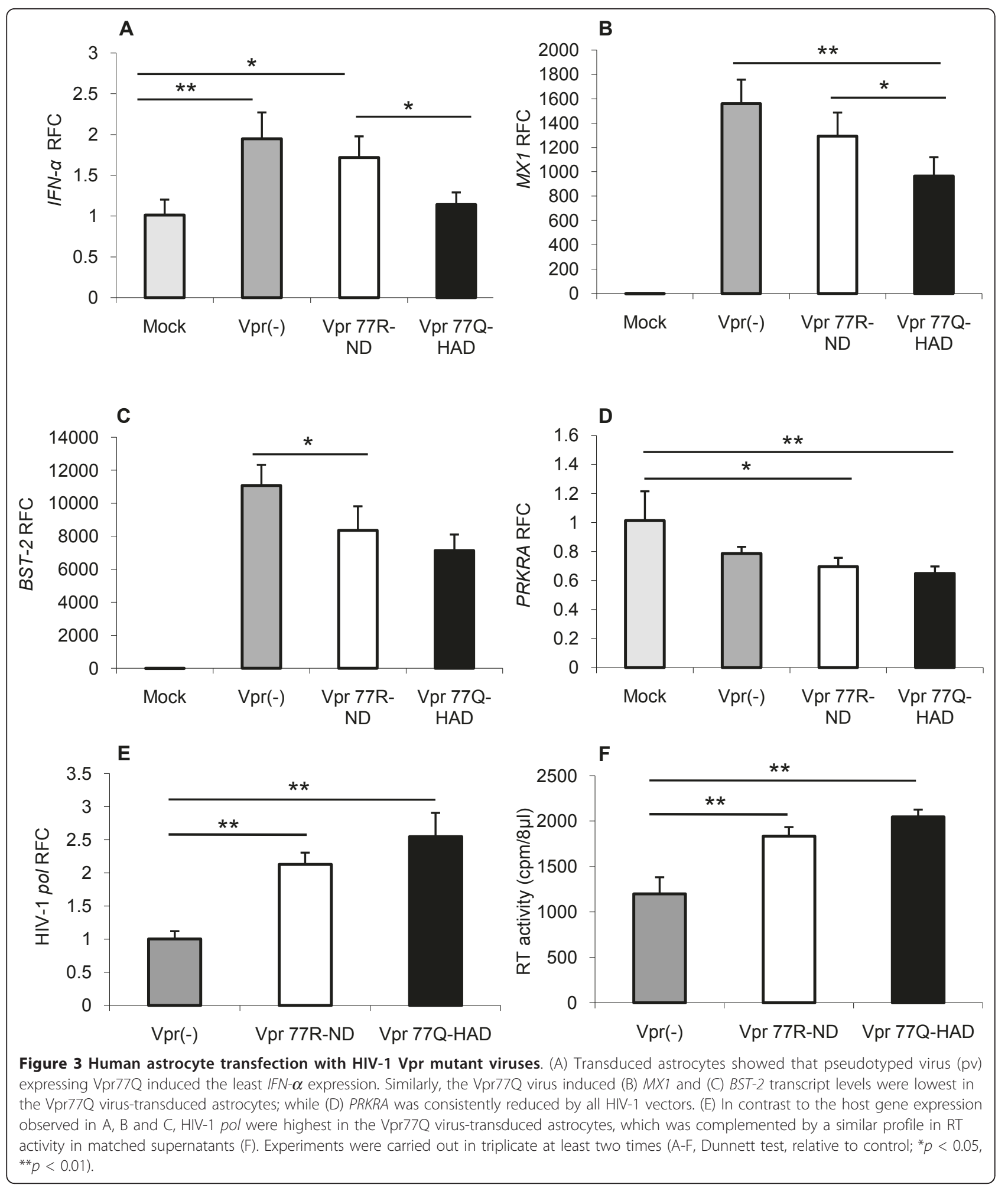

In vivo actions of $\mathrm{Vpr}$ and derived peptides

Vpr causes neurodegeneration and neurobehavioral deficits in transgenic mice selectively expressing $\mathrm{Vpr}$ in microglia [20-22,33]. However, the actions of soluble
Vpr proteins or peptides expressed focally in the brain were unknown. Full length $\mathrm{Vpr}$ (amino acids 1-96), $\Delta$ Vpr77R-ND, $\Delta$ Vpr77Q-HAD or PBS were stereotactically implanted into the striatum of mice and 


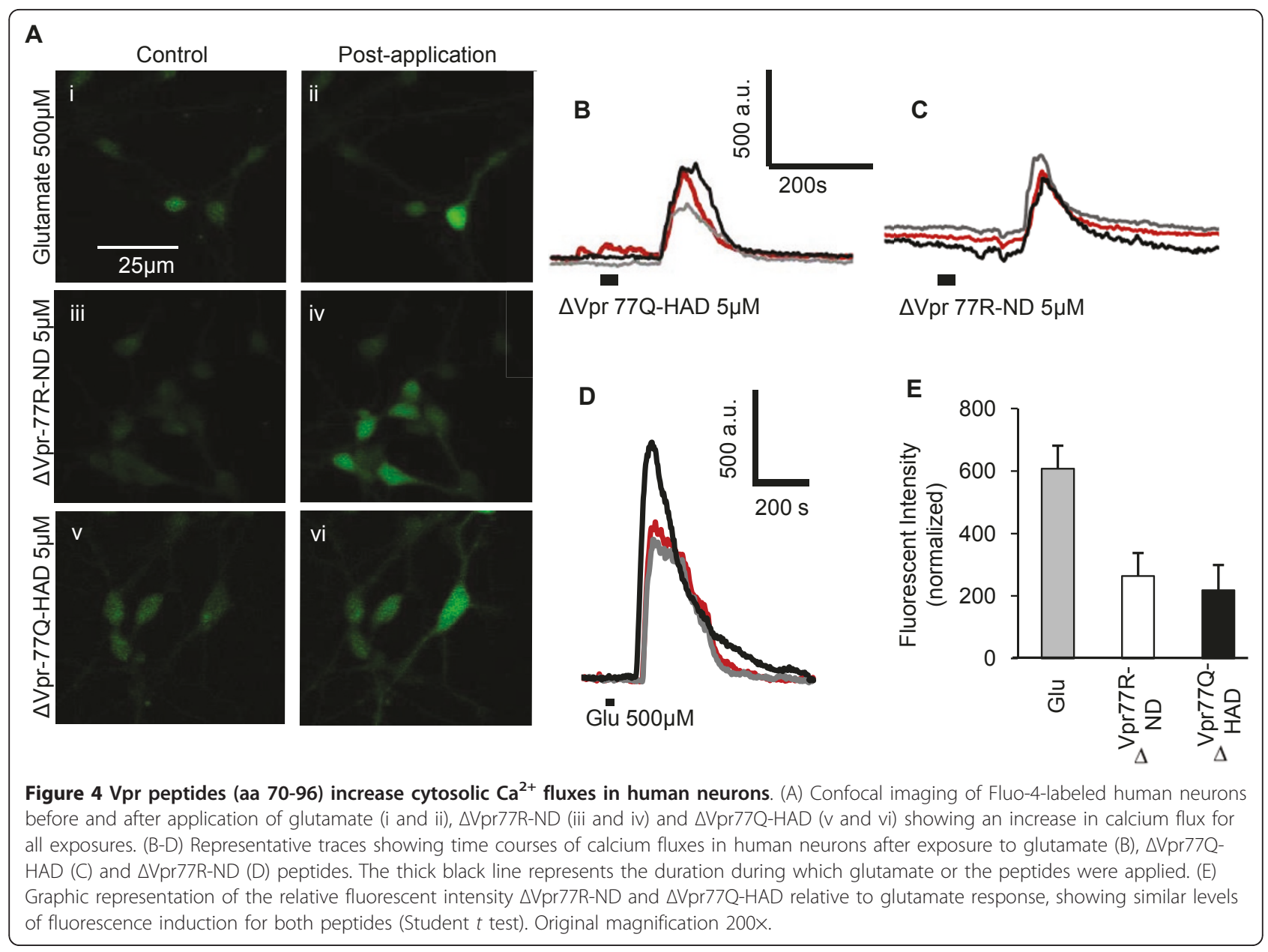

subsequent neuropathological and neurobehavioral studies were performed. Neuropathological studies of the basal ganglia revealed that numerous neurons, identified by their prominent nuclei and nucleoli in Nissl-stained preparations, were present in the basal ganglia of PBSimplanted animals (Figure 6A) but in contrast there were a reduced number of neurons in animal implanted with the full length Vpr- (Figure $6 \mathrm{~B}$ ) and $\Delta$ Vpr77R-ND(Figure 6C). No differences in neuronal abundance from the PBS-implanted animals were observed in the $\triangle$ Vpr77Q-HAD-implanted animals (Figure 6D). Minimal Iba-1 immunoreactivity was evident in the basal ganglia of PBS-implanted animals (Figure 6E) while the numbers of Iba-1 immunopositive microglia were increased in the full length Vpr- (Figure 6F) and $\Delta$ Vpr77R-ND(Figure 6G) implanted animals, reflecting a glial response to cellular injury. Iba- 1 immunoreactivity did not differ between the PBS-implanted animals and the $\triangle$ Vpr77Q-HAD-implanted animals (Figure 6H). GFAP immunoreactivity was readily detected in astrocytes of the PBS-implanted animals (Figure 6I) but was diminished in the full length Vpr- (Figure 6J) and $\Delta \mathrm{Vpr} 77 \mathrm{R}-$
ND- (Figure 6K) implanted animals while GFAP immunoreactivity in the $\triangle \mathrm{Vpr} 77 \mathrm{Q}-\mathrm{HAD}$-implanted animals (Figure 6L) was similar to the PBS-implanted control animals.

To define the neurobehavioral correlates accompanying the neuropathological studies described above, ipsiversive rotary behavior was recorded at days 7,14 , and 28 post-implantation. These studies disclosed that at days 7 (data not shown) and 14, experimental groups displayed similar levels of ipsiversive rotary behavior (Figure 6M). However, at day 28 post-implantation, both full length $V p r$ and each $\triangle$ Vpr77R-ND caused significantly increased rotary behavior compared with PBSimplanted animals (Figure 6N). Thus the latter findings supported the present in vitro and neuropathological findings in that Vpr containing 77R, as a peptide or full length protein, was more neurovirulent compared with the 77Q peptide or controls.

\section{Discussion}

In the present studies, mutations at amino acid position 77 were discovered within brain-derived HIV-1 Vpr 

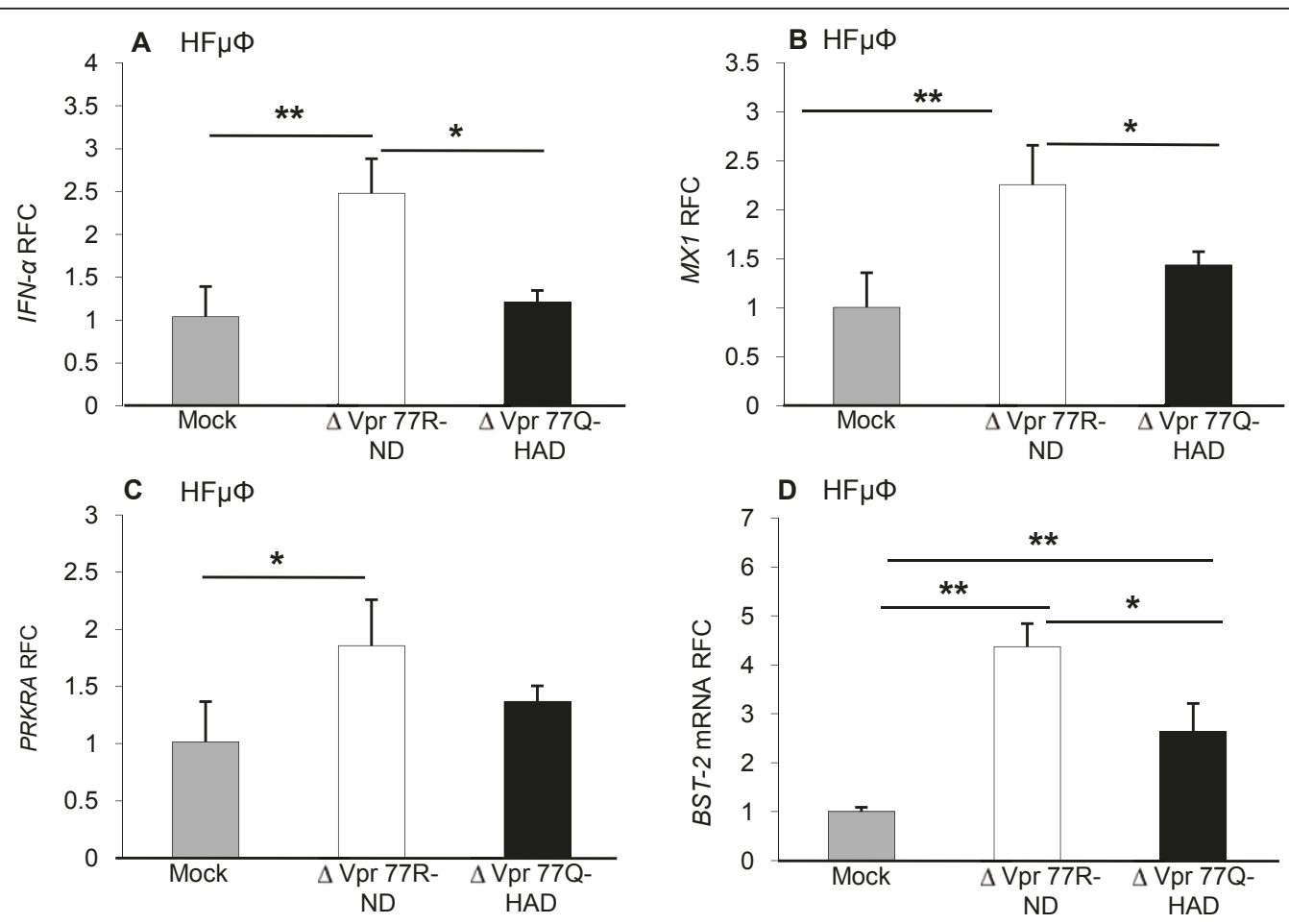

D $\mathrm{HF} \mu \Phi$
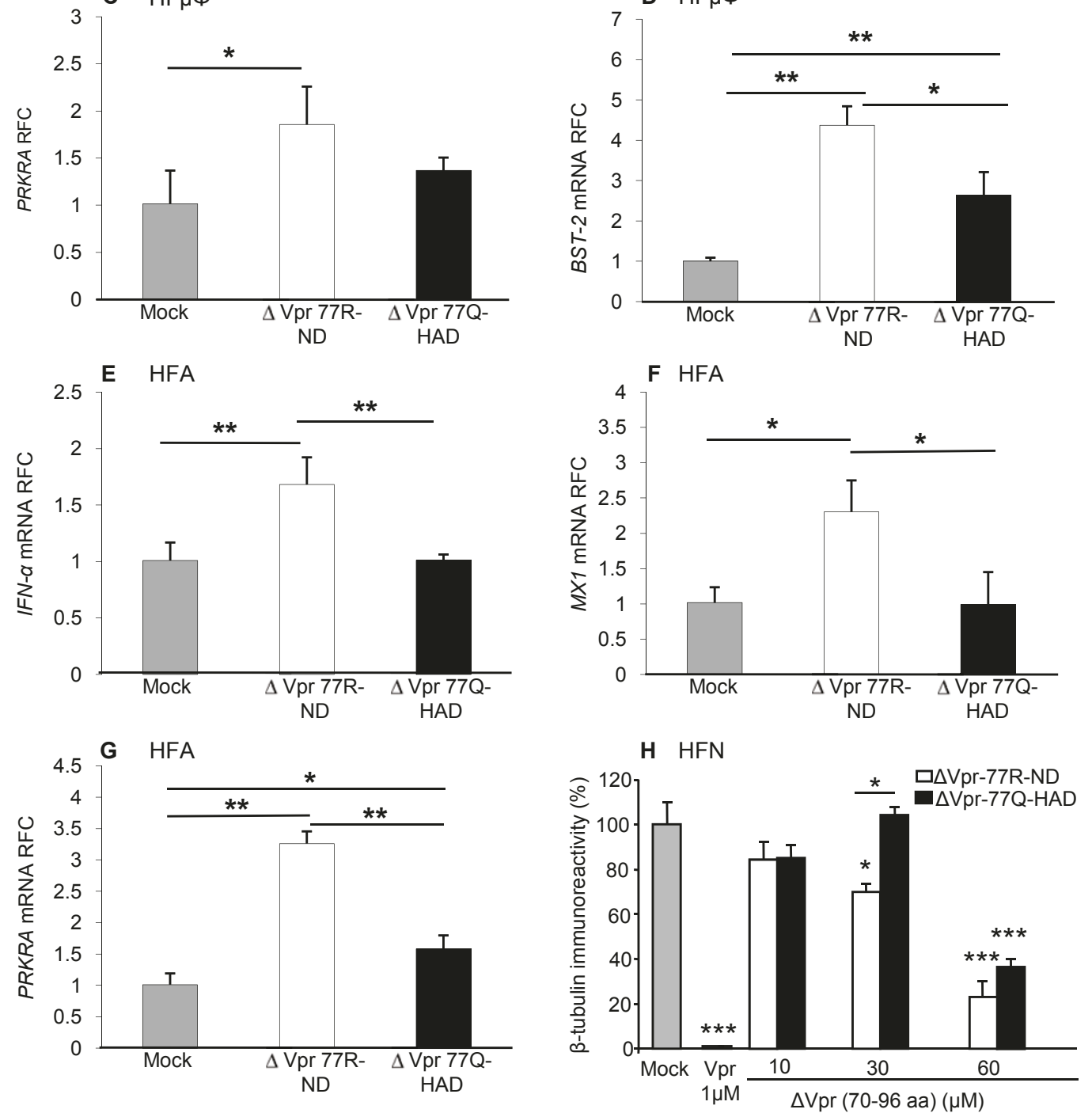

Figure $5 \mathrm{Vpr}$ peptides (aa 70-96) exert neuroimmune and neurotoxic effects. Exposure of $\triangle \operatorname{Vpr} 77 \mathrm{Q}-\mathrm{HAD}(5.0 \mu \mathrm{M})$ or $\triangle \mathrm{Vpr} 77 \mathrm{R}-\mathrm{ND}$ (5.0 $\mu \mathrm{M})$ to human microglia resulted in $\triangle$ Vpr77R-ND-mediated induction of (A) IFN- $\alpha$, (B) MXI, (C) PRKRA and (D) BST-2 transcripts. Similarly, human astrocytes exposed to the same peptides showed induction of (E) IFN- $\alpha$, (F) MXI and (G) PRKRA expression. (H) Exposure of $\triangle V$ pr $77 R-N D$ to human neurons caused a concentration-dependent (10.0-60.0 $\mu \mathrm{M}$ ) reduction in $\beta$-tubulin immunoreactivity while $\triangle \mathrm{Vpr} 77 \mathrm{Q}-\mathrm{HAD}$ showed less neurotoxicity. Full length $\operatorname{Vpr}(1.0 \mu \mathrm{M})$ was also highly neurotoxic. Experiments were carried out in triplicate at least two times (A-D, Dunnett test, relative to control; $\left.{ }^{*} p<0.05,{ }^{*} p<0.01\right)$. 


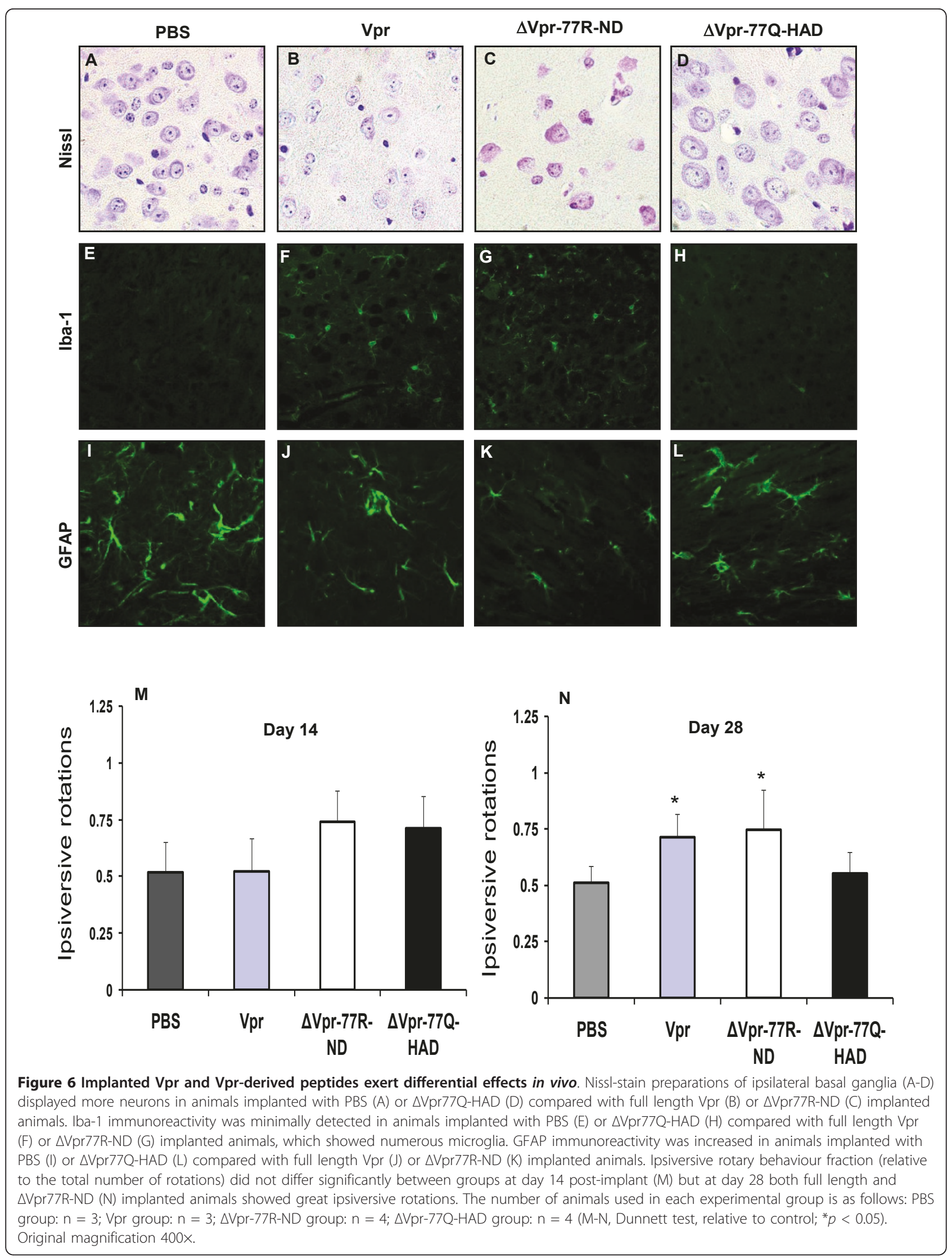


sequences, which distinguished HIV/AIDS patients with (77Q) and without (77R) HIV-associated dementia. Remarkably, these mutations varied in their ability to induce innate immune responses depending on the specific mutation, which were also associated with their neurodegenerative actions. Moreover, $\Delta \mathrm{Vpr}$ peptides (amino acids 70-96), containing the variable amino acid 77 residue, exerted both immunogenic and neurotoxic actions in vitro and in vivo but the ensuing outcomes were influenced by the specific mutation present at position 77 within the peptide. Although the $77 \mathrm{R}$ mutation induced greater antiviral innate immunity and increased neurotoxicity, the $77 \mathrm{Q}$ mutation was associated with higher frequency of detection in human brain and replicated at similar levels to the virus containing the 77R mutation in glial cells. These findings highlighted the complexity of events influenced by HIV-1 molecular diversity, together with the additive effects of viral molecular heterogeneity on host responses and viral replication in the development of neurovirulence.

$\mathrm{Vpr}$ is expressed by the HIV genome later in the viral life cycle but it appears essential for macrophage infection and perhaps microglia tropism. Vpr also mediates apoptosis in multiple cells types, possibly through influencing G2 phase of the cell cycle [15,50-54]. Previous reports indicate that Vpr exhibits neurovirulent properties including alterations in neuronal excitability and ensuing death in vitro as well as synaptic retraction in vivo, accompanied by neurobehavioral abnormalities [20]. As in previous studies, Vpr-derived peptides were neurotoxic [47,55-57] while for full length and the derived peptides, innate immune activation was largely limited to antiviral responses (IFN- $\alpha$ and BST-2 induction) with limited concurrent induction of proinflammatory cytokines (IL-1 $\beta$, TNF- $\alpha$ ). This latter observation highlights Vpr's neurodegenerative aspects, which are not linked per se to pro-inflammatory mechanisms in the nervous system. Regulation of innate immune responses is a pivotal determinant of progression to AIDS but also influences the development of HIVinduced brain disease [58-60]. Type I interferons, interferon (IFN) $-\alpha$ and $-\beta$, exert antiviral effects through multiple pathways including regulation of the expression of several downstream genes including $M X, P R K R A$, and $B S T-2$, all with potential antiviral activities [61-63]. MX proteins are a group of dynamin-like large guanosine triphosphatases (GTPases) enzymes. Some MX GTPases have been shown to exert antiviral effects against a wide range of RNA and some DNA viruses [64]. PRKRA is an interferon-inducible protein kinase, also known as Protein kinase $R$ (PKR)-activating protein, which is involved in PKR-mediated antiviral effects [65]. Likewise, bone marrow stromal cell antigen 2 (BST-2), also termed tetherin, has also been shown to be an IFN- regulated restriction factor for HIV-1 [63,66]. While neuroinflammation is a cardinal feature of HAD, antiviral responses including induction of IFN- $\alpha, \mathrm{MX}-1$, PRKRA or BST-2 await clarification of their expression in HAD, although several studies indicate the IFN- $\alpha$ might be increased in the brains of HIV/AIDS patients [67-69].

Molecular diversity, as well as specific mutations within the HIV-1 genome, has been associated with HIV-induced neurological disease [32,70,71]. In particular, increased diversity within brain-derived HIV-1 envelope sequences from HAD patients is a common finding in several studies [71,72]. Specific mutations and/or motifs within HIV-1 gp120 have also been associated with HAD [73]. Differential sequence diversity within brain-derived Tat and Nef sequences appear to discriminate between HIV/AIDS patients with and without HAD [74-76]. It was shown that astrocytes would harbor provirus only [77], therefore viral genomic RNA used as template for RT-PCR to amplify vpr gene in this study should be derived from perivascular macrophages or microglia. Herein, amino acid position 77 within $\mathrm{Vpr}$ distinguished the two clinical groups, 77Q and 77R in HAD and ND AIDS patients, respectively. Our finding that brain-, but not blood-derived, sequences distinguished HAD from ND AIDS patients implies the motif at position 77 might reflect mutagenesis of the virus within the brain. The 77Q mutation has been associated with sustained non-progression of HIV infection [27,29], while in the present study the same mutation was associated with HAD. Protein sequence alignment of HIV-1 Vpr from 4 HIV-1 B clade strains revealed that prototypic brain-derived viruses, YU2 and JRFL, from patients with HAD exhibited $77 \mathrm{Q}$ while non-brain-derived strains (JR-CSF and NL4-3) show 77R. This comparison suggests that the change from $77 \mathrm{R}$ to $77 \mathrm{Q}$ might be important for both neurotropism and perhaps neurovirulence. Similar to previous studies, the $77 \mathrm{Q}$ motif also exerted less cytotoxic effects and minimal induction of anti-viral immune responses in vitro, suggesting this same mutation also diminished cytopathogenicity [28]. It is widely assumed that HAD represents a state of increased HIV-1 neurovirulence, recapitulating animal studies in which a specific virus causes neurovirulence $[78,79]$. Thus, the present studies raise a dichotomy regarding Vpr's role in neurovirulence: although the $77 \mathrm{Q}$ motif was more frequently detected in brainderived sequences from HAD patients, the same mutation caused less neurotoxicity and a muted antiviral immune response. However, the likelihood of detecting $v p r$ sequences in brain was significantly higher in HAD (Figure 1F) and the viruses encoding Vpr 77Q or 77R replicated similarly in glial cells (Figure $3 \mathrm{E}$ and $3 \mathrm{~F}$ ). Several potential explanations underlie these findings: (a) 
the 77Q mutation with Vpr permits HIV-1 to persist and replicate in the brain by restricting the neuroimmune antiviral response(s) and Vpr's direct neurotoxic effects, thereby augmenting the virus' fitness and replicative capacity, as evidenced by its increased detection in HAD brains and the apparent inability to induce BST-2; (b) the Vpr $77 \mathrm{Q}$ mutation might be an associated or compensatory mutation, which modulates viral replication but is enhanced by other neurovirulenceconferring mutations occurring elsewhere in the HIV genome, thereby preventing the virus from overwhelming the host; (c) the $77 \mathrm{Q}$ confers some as yet unrecognized property on the virus in terms of its neurovirulence, perhaps through its putative effects on phosphorylation of the nearby $79 \mathrm{~S}$ residue within $\mathrm{Vpr}$ $[80,81]$. Regardless of what pathogenic mechanism is mediated by the $77 \mathrm{Q}$ or $-\mathrm{R}$ motifs, the brain is likely an "evolutionary cul-de-sac" for the virus because HIVinduced brain disease predicts worsened survival with or without combination antiretroviral therapy $[82,83]$. The present findings raise a fundamental issue regarding the relationship between virus-mediated neurovirulence and neurological outcomes, suggesting that HAD might be a state of failing neuroimmunity.

The present observations highlight an important aspect of HIV disease progression in a cohort of AIDS patients regarding the role of a comparatively unstudied viral protein found in the brain. However, these studies require verification in a larger cohort and perhaps in patients infected with different HIV-1 clades. The use of the present animal model could be extended by comparing transgenic animals containing each amino acid 77 within the expressed Vpr. Herein GFAP immunoreactivity was diminished in the basal ganglia in brains of mice implanted with the $\Delta \mathrm{Vpr}-77 \mathrm{R}-\mathrm{ND}$ peptide, whereas as it was not significantly altered in the basal ganglia of mice receiving $\triangle \mathrm{Vpr}-77 \mathrm{Q}-\mathrm{HAD}$ peptide (Figure $6 \mathrm{I}-\mathrm{L}$ ), indicating the wild-type but not the mutant $\mathrm{Vpr}$ peptide exerted a cytotoxic effect on astrocytes. Moreover, mice receiving full-length $\mathrm{Vpr}$ injection also showed a reduction in GFAP immunoreactivity, indicative of astrocyte injury/death, which was consistent with recent observations in the brains of Vpr-transgenic animals [84]. Future studies of cerebrospinal fluid (CSF)-derived Vpr alleles might also be a fruitful approach in terms of understanding pathogenesis as well as diagnostic importance, given the availability of CSF early in the disease course.

\section{Conclusions}

These observations suggest that the $77 \mathrm{R}$ mutation within Vpr exerts greater effects on host cell immunity and survival than $77 \mathrm{Q}$, thereby limiting viral expression and perhaps persistence in the brain. However these findings also indicate that HIV-mediated neurovirulence reflects the virus' overall capacity to curb antiviral immune responses through viral mutagenesis coupled with preserving its replicative properties.

\section{Methods}

\section{Human brain and blood samples for RNA isolation, PCR} and sequencing

Genomic RNA was isolated from frontal white matter of brain tissue and peripheral blood mononuclear cells (PBMCs), which were obtained from AIDS-defined HIV-1 seropositive persons who were non-demented (ND) or diagnosed pre-mortem with HAD, using TRIzol reagent (Gibco), as previously reported $[85,86]$. According to the manufacturer's protocol, total RNA was isolated, dissolved in diethylpyrocarbonate (DEPC)-treated water and used for the synthesis of cDNA. The HIV-1 $v p r$ gene was amplified from cDNA using a nested PCR protocol: initial denature step of $2 \mathrm{~min}$ at $94^{\circ} \mathrm{C}$, followed by 35 cycles of $30 \mathrm{~S}$ at $94^{\circ} \mathrm{C}, 30 \mathrm{~S}$ at $52^{\circ} \mathrm{C}, 1 \mathrm{~min}$ at $68^{\circ}$ $\mathrm{C}$, with a final extension step of $7 \mathrm{~min}$ at $72^{\circ} \mathrm{C}$. The forward and reverse primers used were as follows: first round forward primer 5'-CAAGCAGGACATAACAAGGTA G; first round reverse primer 5'TGGCAATG AAAGCAACACT; second round forward primer 5'-CATCTAGAGCAGAGGACAGATGGAACAAG and second round reverse primer 5'-CTAG GCCTTCTAGGATCTACTGGCTCC. PCR fragments corresponding to the amplified $v p r$ gene were isolated from agarose gel using the QiaQuick gel extraction kit (Qiagen), the incomplete fragment ends were filled in with Klenow, phosphorylated using T4 polynucleotide kinase and cloned into the pSL1180 vector (Amersham Biosciences Inc). All reagents were obtained from New England BioLabs Ltd and used following the manufacturer's specifications. PCR fragments or multiple clones of the cloned PCR fragments were sequenced in both directions using the second round PCR forward and reverse primers, as previously reported $[72,76,85]$. DNA sequences were determined by automated sequencing on an ABI 370 sequencer (Applied Biosystems, Streetsville, $\mathrm{ON}$ ) using the manufacturer's protocols and reagents. The sequences obtained from cloned and PCR fragments were aligned using the BioEdit sequence alignment software (Ibis Biosciences, Carlsbad, CA) and used to derive a consensus sequence for each patient group.

\section{Construction of vpr clones}

To clone 96 amino acid HIV-1 vpr gene (derived from HIV-1 NL43), forward primer PHN96-1F 5'-GGG CCCGGGATCCACCGGTCGCCACCATGGAACAAG CCCCAGAAGACC, containing $\mathrm{BamH}$ I restriction site, and reverse primer PHN96-1RM 5'-GGCGGATAC 
CCGCG GCCGCCTAGGATCTACTGGCTCCATTTC, containing Not I restriction sites, were utilized with template of HIV NL4-3 plasmid cDNA to amplified the $v p r$ fragment by PCR. The generated fragment was subsequently digested with $B a m \mathrm{H}$ I and Not I and ligated into a pEGFP-N1 plasmid vector with same restriction enzymes digestion, in which the green fluorescent protein gene was removed. Similarly, a vpr start codon knockout clone was constructed by replacing above primer PHN96-F with PHN96-1FK5'-GGGCCCGGGATCCACCGGTCGCCA CCACGGAACAAGCCCCAGAAGACC, in which ATG was substituted to ACG [37]. To construct the "R77Q" modified HIV vpr (NL43D), primer pairs of PHN96-1F (shown above)/PHN96-3R 5'TCTGCTATGTTGACACCCAATTCTG and PHN961RM (shown above)/PHN96-3F 5'-GTGTCAACATAGCAGAATAGGC were used to generate two overlapping fragments of the $v p r$ gene with template of HIV NL4-3 plasmid for the first PCR. The two generated fragments were fused together in a subsequent extension reaction and amplified by secondary PCR with outside primers PHN96-1F and PHN96-1RM (shown above) and thus generate an entire "R77Q" modified vpr gene fragment flanked with BamH I and Not I restriction site. The entire $v p r$ gene fragment was subsequently cloned into above described GFP vector generating NL4-3. The two $v p r$ constructs, 77R-ND and 77Q-HAD were resequenced to ensure that only the $v p r$ gene sequences of interest were present.

\section{HIV molecular clones' construction}

To evaluate the effects of Vpr mutations on human fetal astrocytes, HIV-1 envelope-defective molecular clones were constructed for transfection. The construction of HIV-1 envelope-defective proviral plasmids, including HxBRUR-/Env-, HxBRUR+/Env-, and HxBRUR+/Env-/ $\operatorname{Vpr}(\mathrm{R} 77 \mathrm{Q})$ was previously described $[27,87,88]$.

\section{Transfection and immunofluorescence detection}

To test expression of cloned HIV-1 Vpr protein, transfection of the cloned HIV-1 vpr plasmid was performed in Crandle feline kidney (CrFK) cells (ATCC) and expression of the $\mathrm{Vpr}$ protein within CrFK cells was subsequently analyzed by immunofluorescent staining. $1.5 \times 10^{5} \mathrm{CrFK}$ cells were cultured on a sterile cover slip in MEM medium supplemented with $10 \%$ fetal bovine serum, penicillin $(100 \mathrm{U} / \mathrm{ml})$, and streptomycin $(100 \mu \mathrm{g} / \mathrm{ml})$ by incubation at 37 degrees Celsius with $5 \%$ $\mathrm{CO}_{2}$ for 24 hours to achieve $>90 \%$ confluency. $1.5 \mu \mathrm{g}$ of $v p r$ plasmid DNA and $5 \mu \mathrm{l}$ of Lipofectamine 2000 (Invitrogen) in $500 \mu \mathrm{l}$ of Opti-MEM medium (Gibco) were transfected into each well according to the manufacturer's protocols. For immunofluorescent staining, supernatants of the overnight transfected CrFK cells were replaced with $1 \mathrm{ml} 2 \%$ (pH7.4) PBS-buffered paraformaldehyde and incubated for $20 \mathrm{~min}$ at room temperature (RT). Cells were washed with PBS $2 \times 5$ min followed by incubation with blocking buffer (PBS/0.2\% Triton/10\% normal goat serum and 2\% BSA) for 1 hour at room temperature. $100 \mu \mathrm{l}$ diluted rabbit anti-vpr primary antibody (1:100 dilution with PBS/0.2\% Triton/5\% normal goat serum and $1 \%$ BSA) was added on each coverslip and incubated for 2 hours at RT. A shaking wash step with PBS $(0.1 \%$ Tween 20$)$ at RT for $3 \times 10$ min was followed incubation with the primary antibody. Subsequently, $100 \mu$ l diluted goat anti-rabbit secondary antibody (Cy3 Conjugated) (1:1000 dilution PBS/0.2\% Triton $/ 5 \%$ normal goat serum and $1 \%$ BSA) was added on each coverslip and incubated for 1 hours at RT. Shaking washes with PBS $(0.1 \%$ Tween 20$)$ at RT for $4 \times$ $15 \mathrm{~min}$ were performed and the coverslips were mounted with Gelvatol on glass slides for confocal laser-scanning microscopy analysis as described previously [20].

\section{Human myeloid cell (U937) transfection by electroporation}

$10 \mu \mathrm{g}$ of cloned $v p r$ plasmid was added to $5 \times 10^{6} \mathrm{U} 937$ cells/reaction which then were re-suspended in $250 \mu \mathrm{l}$ of room temperature RPMI medium (without FBS and $\mathrm{P} / \mathrm{S}$ ). The mixture was then transferred to a 0.4-cm gap cuvette for electroporation. Electroporation was performed at 242 voltage and 975 microfarads for $~ 30$ msec with a Gene Pulser II electroporator (Bio-Rad). The electroporation-transfected U937 cells were cultured in 12 well plates, adding fresh RPMI medium (1 $\mathrm{ml} /$ well) containing $10 \%$ fetal bovine serum, penicillin (100 U/ml), and streptomycin $(100 \mu \mathrm{g} / \mathrm{ml})$, followed by incubation at $37^{\circ} \mathrm{C}$ in $5 \% \mathrm{CO}_{2}$ for 24 hours. At 24 hours post-transfection, culture supernatants were collected for neurotoxicity assays and total cellular RNA was isolated using the TRIzol reagent (Gibco).

Human fetal neuron, astrocyte and microglia cell cultures Human neuronal cultures were prepared from 15-19 week aborted fetal brains obtained with consent (approved by the University of Alberta Ethics Committee), as previously described [86]. Briefly, fetal brain tissues were dissected, meninges were removed, and a single cell suspension was prepared by trituration through serological pipettes, followed by digestion for 30 min with $0.25 \%$ trypsin (Life Technologies, Burlington, ON, Canada) and $0.2 \mathrm{mg} / \mathrm{ml}$ DNase I (Roche Diagnostics, Mannheim, Germany) and passage through a $70-\mu \mathrm{m}$ cell strainer (BD Biosciences, Mississauga, ON, Canada). Cells were washed 2 times with fresh medium and plated in T-75 flasks coated with poly-L-ornithine (Sigma-Aldrich, Oakville, ON, Canada) at 6-8 × 10 
cells/flask and medium for growing human fetal neuron (HFN), astrocyte and microglia cells was subsequently added (named HFN medium), which was MEM supplemented with 10\% FBS (Life Technologies), $2 \mathrm{mM}$ L-glutamine (Life Technologies), $1 \mathrm{mM}$ sodium pyruvate (Life Technologies), $1 \times$ MEM nonessential amino acids (Life Technologies), 0.1\% dextrose (Sigma-Aldrich), $100 \mathrm{U} / \mathrm{ml}$ Penicillin (Life Technologies), $100 \mu \mathrm{g} / \mathrm{ml}$ streptomycin (Life Technologies), $0.5 \mu \mathrm{g} / \mathrm{ml}$ amphotericin B (Life Technologies), and $20 \mu \mathrm{g} / \mathrm{ml}$ gentamicin (Life Technologies). Specifically, for neuronal cultures, $25 \mu \mathrm{M}$ cytosine arabinoside (Sigma-Aldrich) were additionally supplemented to prevent astrocyte growth. Astrocyte cultures, without cytosine arabinoside, were passaged once a week and in 4-6 weeks the neurons were eliminated; the remaining astrocytes were ready for HIV transfection or infection. For microglial cell cultures, suspended microglial cells collected by centrifugation at $1200 \mathrm{rpm}$ for 10 min at one week after cultures were established. The collected microglia cells were grow in a new plate with the above medium (without cytosine arabinoside) and ready for HIV transfection or infection in two days.

\section{Neuronal toxicity assay}

Neurotoxicity assays were performed by methods described previously [20]. Briefly, human fetal neurons described above were cultured in 96-well flat bottom plate with supernatants derived from transfected U937 cells for 48 hours. Cells were then fixed in $4 \%$ formalin, washed in PBS containing 0.1\% Triton-X, blocked for 90 min with LI-COR Odyssey Blocking Buffer (LI-COR, Lincoln, NE). After removal of the blocking reagent, the cells were incubated overnight at $4^{\circ} \mathrm{C}$ with monoclonal mouse anti- $\beta$-tubulin (1:1000 dilution; Sigma-Aldrich). After primary antibody application, the cells were washed in PBS containing 0.1\% Tween-20 and incubated with goat anti-mouse Alexa Flour 680 (1:200 dilution; Invitrogen) secondary antibody. All antibody dilutions were made with LI-COR Odyssey Blocking Buffer. After removal of the secondary antibodies, the cells were washed in PBS/0.1\% Tween 20 and left to dry in the dark before quantification of $\beta$-tubulin immunoreactivity using the Odyssey Infrared Imaging System (LI-COR).

\section{Human astrocyte (HFA) transfection}

The above prepared HFAs were subsequently seeded into 12 well plates at $2 \times 10^{5}$ cells/well and $1 \times 10^{4}$ cells/well, respectively, followed by incubation at 37 degrees Celsius with $5 \% \mathrm{CO}_{2}$ for 24 hours. For each transfection reaction, $2 \mu \mathrm{g}$ of proviral HIV-1 plasmid (HxBRUR+/ENV-, HxBRUR-/ENV- or HxBRUR $+/$ ENV-/ $\operatorname{Vpr}(\mathrm{R} 77 \mathrm{Q}))$ were mixed with $1 \mu \mathrm{l}$ plus reagent (Invitrogen) for 10 minutes. Then $5.5 \mu \mathrm{l}$ of Lipofectamine LTX (Invitrogen) was added to the mixture and incubated for 30 minutes followed by transfection to each well (with $1 \mathrm{ml}$ fresh HFN medium) according to the manufacturer's protocols. At 6 hours post-transfection, transfection medium was removed and $1 \mathrm{ml} /$ well fresh HFN medium was added. At 48 hours post-transfection, culture supernatants containing pseudotyped HIV-1 were collected for viral reverse transcriptase (RT) activity assay and total cellular RNA was isolated from the cultured primary HFAs with using RNeasy Mini Kit (Qiagen) after lysis with TRIzol (Invitrogen) using manufacturer's guidelines. The isolated RNA was used for real time RT-PCR.

\section{Reverse transcriptase (RT) assay}

RT activity in culture supernatants was assayed as previously described [89]. Briefly, $8 \mu \mathrm{l}$ of culture supernatant was incubated with $32 \mu \mathrm{l}$ of reagent buffer containing $[\alpha-32 \mathrm{P}] \mathrm{dTTP}$ for 2 hours at $37^{\circ} \mathrm{C} .30 \mu \mathrm{l}$ reaction mixes were spotted on pencil labeled DE-81 paper squares (Whatman International, Ltd.). Papers were air-dried again for $30 \mathrm{~min}$ and washed 5 times for 10 min with gentle shaking in $100 \mathrm{ml} 2 \times$ SSC and twice for $1 \mathrm{~min}$ in $50 \mathrm{ml}$ 95\% ethanol. Papers were airdried for $30 \mathrm{~min}$ and RT levels were measured by liquid scintillation counting (TRI-CARB 2100TR, PACKARD, USA). All assays were performed in minimum triplicate.

\section{Real time RT-PCR assay}

Total cellular RNA was isolated from cultured U937, primary HFAs using RNeasy Mini Kit (Qiagen) after lysis with TRIzol (Invitrogen) using manufacturer's guidelines. RNA dissolved in DEPC-treated water was used for cDNA synthesis. First-strand cDNA was synthesized by using $500 \mathrm{ng} /$ reaction of the extracted total RNA for subsequent RT-PCR assay as described previously [89]. The prepared first-strand cDNA was diluted 1:1 with sterile water and $5 \mu \mathrm{l}$ were used per PCR. The primers used in the real-time PCR were as follows: GAPDH: forward primer, 5'-AGCCTTCTCCAT GGTGAA; reverse primer, 5'-CGGAGTCAACGGAT TTGGTCG; TNF- $\alpha$ : forward primer, 5'-CCCCA GGGCTCCAGAAGGT; reverse primer, 5'-TGGGGCA GAGGGTT GATTAGTTG; IFN- $\boldsymbol{\alpha}$ : forward primer, 5'GGAGGAGAGGGTGGGAGAAAC; reverse primer, 5'-GAAAGCGTGACCTGGTGTATGAG; $\boldsymbol{M X 1}$ : forward primer, 5'-CGGGGAAGGAATGGG AATCAGTCA; reverse primer, 5'-TTCCGCACCACGTCCACAACCTT; PRKRA: forward primer, 5'-GTCCACCAGCCCCATCACAG; reverse primer, 5'-AGGGGCCAGAGGGGAACT TT; $\boldsymbol{B S T}$-2: forward primer, 5'-AGAAGGGCTTTCAGGATGTG; reverse primer, 5'-CTTTTGT CCTTGG GCCTTCT; HIV-1 Pol: forward primer, 5'-TTAAGACAGCAGTACAAATGGCAG T; reverse primer, 5'ACTGCCCCTTCACCTTTCCA. Semi-quantitative 
analysis was performed by monitoring in real time the increase of the fluorescence of SYBR Green dye on a Bio-Rad I-Cycler IQ detection system. A threshold cycle value for each gene of interest was determined as previously reported [90]. All data was normalized against the matched GAPDH mRNA levels except for U937 electroporation-transfected experiment (Figure 2), which was normalized against the matched $V p r$ mRNA levels.

\section{Soluble Vpr preparation}

The procedure for producing full- length recombinant HIV-1 Vpr protein derived from pNL4-3 has been described previously [91]. In addition, Vpr peptides (7096) were purchased from Alpha Diagnostic International.

\section{Calcium imaging}

Human neuronal cultures were plated in $35 \mathrm{~mm}$ tissue culture dishes (VWR). The 2-5 days old cultures treated with $5 \mu \mathrm{M}$ Fluo-8 acetoxymethyl ester (Fluo-8-AM) for 30 minutes were imaged as previously described [92]. Changes in $\mathrm{Ca}^{2+}$ induced fluorescence intensity were evoked by glutamate ( $500 \mu \mathrm{M}, 60 \mathrm{~s}$ application) and $\mathrm{Vpr}$ peptides and were measured using a confocal microscope equipped with an argon (488 nm) laser and filters $(20 \times$ XLUMPlanF1, NA 0.95 objective; Olympus FV300, Markham, Ontario, Canada). Full frame images $(512 \times 512$ pixels $)$ were acquired at a scanning time of 3 $\mathrm{s}$ per frame. Selected regions of interest were drawn around distinct cell bodies and traces of time course of change of fluorescence intensity were generated with FluoView v.4.3 (Olympus). Data were only collected from cells in the plane of focus that responded reversibly to a glutamate challenge. Data were collected from 1-5 neurons in each $35 \mathrm{~mm}$ dish.

\section{In vivo mouse model}

Three-week-old male CD-1 mice were obtained from Charles River Laboratories (Wilmington, MA) and housed in a biocontainment facility according to the guidelines of the Canadian Animal Care Committee. All behavioral testing was performed as described previously [93] by an experimenter blinded to the specific transgenic groups. Animals were placed in a stereotaxic frame under ketamine/xylazine anaesthesia. Full length Vpr $(400 \mu \mathrm{M}, 2 \mu \mathrm{l} /$ each animal), Peptides $(20 \mathrm{mM}, 2 \mu \mathrm{l} /$ each animal) and PBS $(2 \mu \mathrm{l})$ were delivered into the striatum of the animals. In vivo neurological injury was assessed according to the Ungerstedt model [94]. In short, ipsiversive rotations as well as total rotations were monitored over $10 \mathrm{~min}$ after intraperitoneal injection of amphetamine $(1 \mathrm{mg} / \mathrm{kg})$ on days $7,14,21$, and 28 following striatal injections. More ipsiversive rotations or less total rotations are both indicative of neurological injury. Animals were sacrificed upon completion of the behavioral studies, brains were removed and immersion fixed in $4 \%$ paraformaldehyde.

\section{Tissue preparation and staining}

Immunofluorescent labelling was performed using $5 \mu \mathrm{m}$ paraffin-embedded serial fixed mouse brain sections, prepared as previously described [95]. Briefly, coronal brain sections were deparaffinized and hydrated using decreasing concentrations of ethanol. Antigen retrieval was performed by boiling the slides in $0.01 \mathrm{M}$ trisodium citrate buffer, $\mathrm{pH}$ 6.0, for $10 \mathrm{~min}$. Sections were blocked in PBS containing 10\% normal goat serum (NGS), $2 \%$ bovine serum albumin and $0.1 \%$ Triton X-100 overnight at $4{ }^{\circ} \mathrm{C}$. The sections were incubated overnight at $4^{\circ} \mathrm{C}$ with antibodies against ionized calcium binding adaptor molecule (Iba-1; 1:200; Wako, Tokyo, Japan) and glial fibrillary acidic protein (GFAP; 1:200; DAKO, Carpinteria, CA, USA), washed in PBS, then incubated with Alexa 488 conjugated goat anti-rabbit or mouse (1:2500 dilution; molecular probes, Eugene, OR) for 1 hour at room temperature in the dark followed by repeated washing in PBS. The sections were finally mounted with Gelvatol and examined with a Zeiss Axioskop 2 upright microscope (Oberkochen, Germany). The sections for Nissl staining were deparaffinized in 3 changes of xylene and hydrated using decreasing concentrations of ethanol. Slides were then stained in $0.1 \%$ cresyl violet solution (Sigma-Aldrich, Oakville, ON, Canada) for 10 minutes and rinsed quickly in distilled water, and differentiated in $95 \%$ ethanol. Finally the slides were dehydrated in $100 \%$ ethanol, cleared in xylene, mounted with Acrytol (Surgipath, Canada), and examined with a Zeiss Axioskop 2 upright microscope (Oberkochen, Germany).

\section{Statistical analyses}

Statistical analyses were performed using GraphPad InStat version 3.0 (GraphPad Software, San Diego, CA), using ANOVA, for mRNA alterations and neurobehavioral analyses. Unless otherwise stated, all post-hoc significant comparisons indicate differences between the control group(s). $p$ values $<0.05$ were considered significant.

\section{Abbreviations}

HIV: human immunodeficiency virus; Vpr: viral protein R; HAD: HIV-associated dementia; AIDS: Acquired immunodeficiency syndrome; ND: non-demented; PKR: Protein kinase R; HF $\mu \varphi$ : human fetal microglial cells; HFN: human fetal neuron; HFA: human fetal astrocytes; CrFK: Crandle feline kidney; pv: pseudotyped viruses; NGS: normal goat serum.

\section{Acknowledgements}

We thank Drs. Marianna Bego and Rakesh K. Bhat for assistance with manuscript preparation and critical review. We also thank Krista Nelles for assistance with manuscript preparation. HN, PV, FN were supported by the Alberta Heritage Foundation for Medical Research (AHFMR) through 
Fellowship awards. CAP was supported by NIH-NIDA K08 DA 16160. CP holds an AHFMR Senior Scholar award and a Canada Research Chair in Neurological Infection and Immunity. These studies were supported by the Canadian Institutes for Health Research (CP). The funders had no role in study design, data collection and analysis, decision to publish, or preparation of the manuscript.

\section{Author details}

'Department of Medicine University of Alberta, Edmonton, AB, T6G 2S2, Canada. ${ }^{2}$ Department of Medical Microbiology \& Immunology, University of Alberta, Edmonton, AB, T6G 2S2, Canada. ${ }^{3}$ Department of Physiology, University of Alberta, Edmonton, AB, T6G 2S2, Canada. ${ }^{4}$ Department of Clinical Neurosciences, University of Calgary, Calgary, AB, T2N 1N4, Canada. ${ }^{5}$ Department of Pharmacology, Faculty of Science, Mahidol University, Rama IV road, Bangkok, 10400, Thailand. 'Department of Neurology and Pathology, Johns Hopkins University School of Medicine, Baltimore, MD 21287, USA. ${ }^{7}$ Institut de recherches cliniques de Montréal (IRCM) and Department of Microbiology and Immunology, Université de Montréal, 110, Pine Avenue, Montreal, Quebec, H2W 1R7, Canada.

\section{Authors' contributions}

CPO and HN conceived and designed the study. HN, assisted by PV and FN, carried out cell transfection, infection, immunostaining and real time RT-PCR experiments; GJ and NB performed patients' sample sequencing; SA carried out calcium imaging studies; FM completed the in vivo experiments; EC made proviral HIV-1 plasmids; HN, SA, FN and FM performed statistical analysis. EC, KB and CPa made substantial contributions to the conception and experimental design of the study, CPO, assisted by HN, SA and FM, wrote the manuscript. All authors have read and approved the final version of the manuscript and have no commercial interests in the manuscript.

\section{Competing interests}

The authors declare that they have no competing interests.

Received: 24 January 2011 Accepted: 6 June 2011

Published: 6 June 2011

\section{References}

1. Chen LF, Hoy J, Lewin SR: Ten years of highly active antiretroviral therapy for HIV infection. Med J Aust 2007, 186:146-151.

2. Barouch $\mathrm{DH}$ : Challenges in the development of an HIV-1 vaccine. Nature 2008, 455:613-619.

3. Jaskolski M, Alexandratos JN, Bujacz G, Wlodawer A: Piecing together the structure of retroviral integrase, an important target in AIDS therapy. FEBS J 2009, 276:2926-2946.

4. Nikolopoulos G, Bonovas S, Tsantes A, Sitaras NM: HIV/AIDS: recent advances in antiretroviral agents. Mini Rev Med Chem 2009, 9:900-910.

5. Woodman Z, Williamson C: HIV molecular epidemiology: transmission and adaptation to human populations. Curr Opin HIV AIDS 2009, 4:247-252.

6. Letendre SL, McCutchan JA, Childers ME, Woods SP, Lazzaretto D, Heaton RK, Grant I, Ellis RJ: Enhancing antiretroviral therapy for human immunodeficiency virus cognitive disorders. Ann Neurol 2004, 56:416-423.

7. Langford D, Marquie-Beck J, de Almeida S, Lazzaretto D, Letendre S, Grant I, McCutchan JA, Masliah E, Ellis RJ: Relationship of antiretroviral treatment to postmortem brain tissue viral load in human immunodeficiency virusinfected patients. J Neurovirol 2006, 12:100-107.

8. Wynn HE, Brundage RC, Fletcher CV: Clinical implications of CNS penetration of antiretroviral drugs. CNS Drugs 2002, 16:595-609.

9. McArthur JC, Brew BJ, Nath A: Neurological complications of HIV infection. Lancet Neurol 2005, 4:543-555.

10. Gonzalez-Scarano F, Martin-Garcia J: The neuropathogenesis of AIDS. Nat Rev Immunol 2005, 5:69-81.

11. Jayadev S, Garden GA: Host and viral factors influencing the pathogenesis of HIV-associated neurocognitive disorders. J Neuroimmune Pharmacol 2009, 4:175-189.

12. Petito CK, Kerza-Kwiatecki AP, Gendelman HE, McCarthy M, Nath A, Podack ER, Shapshak P, Wiley CA: Review: neuronal injury in HIV infection. J Neurovirol 1999, 5:327-341.

13. Doble A: The role of excitotoxicity in neurodegenerative disease: implications for therapy. Pharmacol Ther 1999, 81:163-221.
14. Nishida K, Markey SP, Kustova Y, Morse HC, Skolnick P, Basile AS, Sei Y: Increased brain levels of platelet-activating factor in a murine acquired immune deficiency syndrome are NMDA receptor-mediated. J Neurochem 1996, 66:433-435.

15. Andersen $J$, Le Rouzic E, Planelles V: HIV-1 Vpr: mechanisms of $G 2$ arrest and apoptosis. Exp Mol Pathol 2008, 85:2-10.

16. Moon HS, Yang JS: Role of HIV Vpr as a regulator of apoptosis and an effector on bystander cells. Mol Cells 2006, 21:7-20.

17. Miles MC, Janket ML, Wheeler ED, Chattopadhyay A, Majumder B, Dericco J, Schafer EA, Ayyavoo V: Molecular and functional characterization of a novel splice variant of ANKHD1 that lacks the $\mathrm{KH}$ domain and its role in cell survival and apoptosis. FEBS J 2005, 272:4091-4102.

18. Planelles $V$, Benichou $S$ : Vpr and its interactions with cellular proteins. Curr Top Microbiol Immunol 339:177-200.

19. Kilareski EM, Shah S, Nonnemacher MR, Wigdahl B: Regulation of HIV-1 transcription in cells of the monocyte-macrophage lineage. Retrovirology 2009, 6:118.

20. Jones GJ, Barsby NL, Cohen EA, Holden J, Harris K, Dickie P, Jhamandas J, Power C: HIV-1 Vpr causes neuronal apoptosis and in vivo neurodegeneration. J Neurosci 2007, 27:3703-3711.

21. Kitayama H, Miura Y, Ando Y, Hoshino S, Ishizaka Y, Koyanagi Y: Human immunodeficiency virus type $1 \mathrm{Vpr}$ inhibits axonal outgrowth through induction of mitochondrial dysfunction. J Virol 2008, 82:2528-2542

22. Patel CA, Mukhtar M, Pomerantz RJ: Human immunodeficiency virus type $1 \mathrm{Vpr}$ induces apoptosis in human neuronal cells. J Virol 2000, 74:9717-9726.

23. Sanchez MS, Grant RM, Porco TC, Getz WM: HIV drug-resistant strains as epidemiologic sentinels. Emerg Infect Dis 2006, 12:191-197.

24. Smit TK, Brew BJ, Tourtellotte W, Morgello S, Gelman BB, Saksena NK: Independent evolution of human immunodeficiency virus (HIV) drug resistance mutations in diverse areas of the brain in HIV-infected patients, with and without dementia, on antiretroviral treatment. J Virol 2004, 78:10133-10148.

25. Tcherepanova I, Starr A, Lackford B, Adams MD, Routy JP, Boulassel MR, Calderhead D, Healey D, Nicolette C: The immunosuppressive properties of the HIV Vpr protein are linked to a single highly conserved residue, R90. PLoS One 2009, 4:e5853.

26. Nakaya T, Fujinaga K, Kishi M, Oka S, Kurata T, Jones IM, Ikuta K: Nonsense mutations in the vpr gene of HIV-1 during in vitro virus passage and in HIV-1 carrier-derived peripheral blood mononuclear cells. FEBS Lett 1994, 354:17-22.

27. Lum JJ, Cohen OJ, Nie Z, Weaver JG, Gomez TS, Yao XJ, Lynch D, Pilon AA, Hawley N, Kim JE, et al: Vpr R77Q is associated with long-term nonprogressive HIV infection and impaired induction of apoptosis. J Clin Invest 2003, 111:1547-1554.

28. Rajan D, Wildum S, Rucker E, Schindler M, Kirchhoff F: Effect of R77Q, R77A and R80A changes in Vpr on HIV-1 replication and CD4 T cell depletion in human lymphoid tissue ex vivo. AIDS 2006, 20:831-836.

29. Mologni D, Citterio P, Menzaghi B, Zanone Poma B, Riva C, Broggini V, Sinicco A, Milazzo L, Adorni F, Rusconi S, et al: Vpr and HIV-1 disease progression: $\mathrm{R} 77 \mathrm{Q}$ mutation is associated with long-term control of HIV1 infection in different groups of patients. AIDS 2006, 20:567-574.

30. Pomerantz RJ: Effects of HIV-1 Vpr on neuroinvasion and neuropathogenesis. DNA Cell Biol 2004, 23:227-238.

31. Mattson MP, Haughey NJ, Nath A: Cell death in HIV dementia. Cell Death Differ 2005, 12(Suppl 1):893-904.

32. van Marle G, Power C: Human immunodeficiency virus type 1 genetic diversity in the nervous system: evolutionary epiphenomenon or disease determinant? J Neurovirol 2005, 11:107-128.

33. Wheeler ED, Achim CL, Ayyavoo V: Immunodetection of human immunodeficiency virus type 1 (HIV-1) Vpr in brain tissue of HIV-1 encephalitic patients. J Neurovirol 2006, 12:200-210.

34. Ayyavoo V, Mahalingam S, Rafaeli Y, Kudchodkar S, Chang D, Nagashunmugam T, Williams WV, Weiner DB: HIV-1 viral protein R (Vpr) regulates viral replication and cellular proliferation in T cells and monocytoid cells in vitro. J Leukoc Biol 1997, 62:93-99.

35. Yadav A, Collman RG: CNS Inflammation and Macrophage/Microglial Biology Associated with HIV-1 Infection. J Neuroimmune Pharmacol 2009.

36. Chui C, Cheung PK, Brumme CJ, Mo T, Brumme ZL, Montaner JS, Badley AD, Harrigan PR: HIV VprR77Q mutation does not influence clinical 
response of individuals initiating highly active antiretroviral therapy. AIDS Res Hum Retroviruses 2006, 22:615-618.

37. Irie T, Nagata N, Yoshida T, Sakaguchi T: Paramyxovirus Sendai virus $C$ proteins are essential for maintenance of negative-sense RNA genome in virus particles. Virology 2008, 374:495-505.

38. Majumder B, Janket ML, Schafer EA, Schaubert K, Huang XL, Kan-Mitchell J, Rinaldo CR Jr, Ayyavoo V: Human immunodeficiency virus type $1 \mathrm{Vpr}$ impairs dendritic cell maturation and T-cell activation: implications for viral immune escape. J Virol 2005, 79:7990-8003.

39. Muthumani K, Choo AY, Hwang DS, Dayes NS, Chattergoon M, Mayilvahanan S, Thieu KP, Buckley PT, Emmanuel J, Premkumar A, Weiner DB: HIV-1 Viral protein-r (Vpr) protects against lethal superantigen challenge while maintaining homeostatic T cell levels in vivo. Mol Ther 2005, 12:910-921.

40. Muthumani K, Hwang DS, Choo AY, Mayilvahanan S, Dayes NS, Thieu KP, Weiner DB: HIV-1 Vpr inhibits the maturation and activation of macrophages and dendritic cells in vitro. Int Immunol 2005, 17:103-116.

41. Kamata M, Wu RP, An DS, Saxe JP, Damoiseaux R, Phelps ME, Huang J, Chen IS: Cell-based chemical genetic screen identifies damnacanthal as an inhibitor of HIV-1 Vpr induced cell death. Biochem Biophys Res Commun 2006, 348:1101-1106.

42. Wang JJ, Lu Y, Ratner L: Particle assembly and Vpr expression in human immunodeficiency virus type 1-infected cells demonstrated by immunoelectron microscopy. J Gen Virol 1994, 75(Pt 10):2607-2614

43. Vodicka MA, Koepp DM, Silver PA, Emerman M: HIV-1 Vpr interacts with the nuclear transport pathway to promote macrophage infection. Genes Dev 1998, 12:175-185.

44. Sherman MP, De Noronha CM, Williams SA, Greene WC: Insights into the biology of HIV-1 viral protein R. DNA Cell Biol 2002, 21:679-688.

45. Mahalingam S, Ayyavoo V, Patel M, Kieber-Emmons T, Weiner DB: Nuclear import, virion incorporation, and cell cycle arrest/differentiation are mediated by distinct functional domains of human immunodeficiency virus type 1 Vpr. J Virol 1997, 71:6339-6347.

46. Levy DN, Refaeli Y, MacGregor RR, Weiner DB: Serum Vpr regulates productive infection and latency of human immunodeficiency virus type 1. Proc Natl Acad Sci USA 1994, 91:10873-10877.

47. Sabbah EN, Roques BP: Critical implication of the (70-96) domain of human immunodeficiency virus type $1 \mathrm{Vpr}$ protein in apoptosis of primary rat cortical and striatal neurons. J Neurovirol 2005, 11:489-502.

48. Amini S, Khalili K, Sawaya BE: Effect of HIV-1 Vpr on cell cycle regulators. DNA Cell Biol 2004, 23:249-260.

49. Patel CA, Mukhtar M, Harley S, Kulkosky J, Pomerantz RJ: Lentiviral expression of HIV-1 Vpr induces apoptosis in human neurons. J Neurovirol 2002, 8:86-99.

50. Conti L, Rainaldi G, Matarrese P, Varano B, Rivabene R, Columba S, Sato A, Belardelli F, Malorni W, Gessani S: The HIV-1 vpr protein acts as a negative regulator of apoptosis in a human lymphoblastoid T cell line: possible implications for the pathogenesis of AIDS. J Exp Med 1998, 187:403-413.

51. Snyder A, Alsauskas Z, Gong P, Rosenstiel PE, Klotman ME, Klotman PE, Ross MJ: FAT10: a novel mediator of Vpr-induced apoptosis in human immunodeficiency virus-associated nephropathy. J Virol 2009, 83:11983-11988.

52. Andersen $J$, DeHart JL, Zimmerman ES, Ardon O, Kim B, Jacquot G, Benichou S, Planelles V: HIV-1 Vpr-induced apoptosis is cell cycle dependent and requires Bax but not ANT. PLoS Pathog 2006, 2:e127.

53. Roshal M, Zhu Y, Planelles V: Apoptosis in AIDS. Apoptosis 2001, 6:103-116.

54. Xiao Y, Chen G, Richard J, Rougeau N, Li H, Seidah NG, Cohen EA: Cellsurface processing of extracellular human immunodeficiency virus type 1 Vpr by proprotein convertases. Virology 2008, 372:384-397.

55. Ferri KF, Jacotot E, Blanco J, Este JA, Kroemer G: Mitochondrial control of cell death induced by HIV-1-encoded proteins. Ann N Y Acad Sci 2000, 926:149-164

56. Piller SC, Ewart GD, Jans DA, Gage PW, Cox GB: The amino-terminal region of Vpr from human immunodeficiency virus type 1 forms ion channels and kills neurons. J Virol 1999, 73:4230-4238.

57. van de Bovenkamp M, Nottet HS, Pereira CF: Interactions of human immunodeficiency virus- 1 proteins with neurons: possible role in the development of human immunodeficiency virus-1-associated dementia. Eur J Clin Invest 2002, 32:619-627.

58. Persidsky Y, Poluektova L: Immune privilege and HIV-1 persistence in the CNS. Immunol Rev 2006, 213:180-194.
59. Clerici M, Stocks NI, Zajac RA, Boswell RN, Bernstein DC, Mann DL, Shearer GM, Berzofsky JA: Interleukin-2 production used to detect antigenic peptide recognition by T-helper lymphocytes from asymptomatic HIV-seropositive individuals. Nature 1989, 339:383-385.

60. DeVico AL, Gallo RC: Control of HIV-1 infection by soluble factors of the immune response. Nat Rev Microbiol 2004, 2:401-413.

61. Haller O, Staeheli P, Kochs G: Interferon-induced Mx proteins in antiviral host defense. Biochimie 2007, 89:812-818.

62. Sadler AJ, Williams BR: Interferon-inducible antiviral effectors. Nat Rev Immunol 2008, 8:559-568.

63. Van Damme N, Goff D, Katsura C, Jorgenson RL, Mitchell R, Johnson MC, Stephens EB, Guatelli J: The interferon-induced protein BST-2 restricts HIV-1 release and is downregulated from the cell surface by the viral Vpu protein. Cell Host Microbe 2008, 3:245-252.

64. Haller O, Staeheli P, Kochs G: Protective role of interferon-induced Mx GTPases against influenza viruses. Rev Sci Tech 2009, 28:219-231.

65. Daher A, Laraki G, Singh M, Melendez-Pena CE, Bannwarth S, Peters AH, Meurs EF, Braun RE, Patel RC, Gatignol A: TRBP control of PACT-induced phosphorylation of protein kinase $\mathrm{R}$ is reversed by stress. Mol Cell Biol 2009, 29:254-265.

66. Tokarev A, Skasko M, Fitzpatrick K, Guatelli J: Antiviral activity of the interferon-induced cellular protein BST-2/tetherin. AIDS Res Hum Retroviruses 2009, 25:1197-1210.

67. Rho MB, Wesselingh S, Glass JD, McArthur JC, Choi S, Griffin J, Tyor WR: A potential role for interferon-alpha in the pathogenesis of HIV-associated dementia. Brain Behav Immun 1995, 9:366-377.

68. Sas AR, Bimonte-Nelson H, Smothers CT, Woodward J, Tyor WR: Interferonalpha causes neuronal dysfunction in encephalitis. J Neurosci 2009, 29:3948-3955.

69. Raber J, Sorg O, Horn TF, Yu N, Koob GF, Campbell IL, Bloom FE: Inflammatory cytokines: putative regulators of neuronal and neuroendocrine function. Brain Res Brain Res Rev 1998, 26:320-326.

70. Ritola K, Robertson K, Fiscus SA, Hall C, Swanstrom R: Increased human immunodeficiency virus type 1 (HIV-1) env compartmentalization in the presence of HIV-1-associated dementia. J Virol 2005, 79:10830-10834.

71. Power C, McArthur JC, Nath A, Wehrly K, Mayne M, Nishio J, Langelier T, Johnson RT, Chesebro B: Neuronal death induced by brain-derived human immunodeficiency virus type 1 envelope genes differs between demented and nondemented AIDS patients. J Virol 1998, 72:9045-9053.

72. Power C, MCArthur JC, Johnson RT, Griffin DE, Glass JD, Perryman S, Chesebro B: Demented and nondemented patients with AIDS differ in brain-derived human immunodeficiency virus type 1 envelope sequences. J Virol 1994, 68:4643-4649.

73. Dunfee RL, Thomas ER, Wang J, Kunstman K, Wolinsky SM, Gabuzda D: Loss of the N-linked glycosylation site at position 386 in the HIV envelope V4 region enhances macrophage tropism and is associated with dementia. Virology 2007, 367:222-234.

74. Bratanich AC, Liu C, McArthur JC, Fudyk T, Glass JD, Mittoo S, Klassen GA, Power C: Brain-derived HIV-1 tat sequences from AIDS patients with dementia show increased molecular heterogeneity. J Neurovirol 1998, 4:387-393.

75. Mayne M, Bratanich AC, Chen P, Rana F, Nath A, Power C: HIV-1 tat molecular diversity and induction of TNF-alpha: implications for HIVinduced neurological disease. Neuroimmunomodulation 1998, 5:184-192.

76. Van Marle G, Rourke SB, Zhang K, Silva C, Ethier J, Gill MJ, Power C: HIV dementia patients exhibit reduced viral neutralization and increased envelope sequence diversity in blood and brain. AIDS 2002, 16:1905-1914.

77. Churchill MJ, Wesselingh SL, Cowley D, Pardo CA, MCArthur JC, Brew BJ, Gorry PR: Extensive astrocyte infection is prominent in human immunodeficiency virus-associated dementia. Ann Neurol 2009, 66:253-258.

78. Tucker PC, Lee SH, Bui N, Martinie D, Griffin DE: Amino acid changes in the Sindbis virus E2 glycoprotein that increase neurovirulence improve entry into neuroblastoma cells. J Virol 1997, 71:6106-6112.

79. Zink MC, Spelman JP, Robinson RB, Clements JE: SIV infection of macaques-modeling the progression to AIDS dementia. J Neurovirol 1998, 4:249-259.

80. Zhou Y, Ratner L: Phosphorylation of human immunodeficiency virus type 1 Vpr regulates cell cycle arrest. J Virol 2000, 74:6520-6527.

81. Agostini I, Popov S, Hao T, Li JH, Dubrovsky L, Chaika O, Chaika N, Lewis R, Bukrinsky M: Phosphorylation of Vpr regulates HIV type 1 nuclear import and macrophage infection. AIDS Res Hum Retroviruses 2002, 18:283-288. 
82. McArthur JC, Hoover DR, Bacellar H, Miller EN, Cohen BA, Becker JT, Graham NM, McArthur JH, Selnes OA, Jacobson LP, et al: Dementia in AIDS patients: incidence and risk factors. Multicenter AIDS Cohort Study. Neurology 1993, 43:2245-2252.

83. Vivithanaporn P, Heo G, Gamble J, Krentz H, Hoke A, Gill J, Power C: Neurologic disease burden in treated HIV/AIDS predicts survival: a population-based study. Neurology 2010.

84. Noorbakhsh F, Ramachandran R, Barsby B, Ellestad KK, LeBlanc A, Dickie P, Baker G, Hollenberg MD, Cohen EA, Power C: MicroRNA profiling reveals new aspects of HIV neurodegeneration: caspase-6 regulates astrocyte survival. The FASEB Journal 2010.

85. van Marle G, Henry S, Todoruk T, Sullivan A, Silva C, Rourke SB, Holden J, McArthur JC, Gill MJ, Power C: Human immunodeficiency virus type 1 Nef protein mediates neural cell death: a neurotoxic role for IP-10. Virology 2004, 329:302-318.

86. Zhu Y, Vergote D, Pardo C, Noorbakhsh F, McArthur JC, Hollenberg MD, Overall CM, Power C: CXCR3 activation by lentivirus infection suppresses neuronal autophagy: neuroprotective effects of antiretroviral therapy. FASEB J 2009, 23:2928-2941.

87. Yao XJ, Mouland AJ, Subbramanian RA, Forget J, Rougeau N, Bergeron D, Cohen EA: Vpr stimulates viral expression and induces cell killing in human immunodeficiency virus type 1-infected dividing Jurkat T cells. J Virol 1998, 72:4686-4693.

88. Subbramanian RA, Yao XJ, Dilhuydy H, Rougeau N, Bergeron D, Robitaille Y, Cohen EA: Human immunodeficiency virus type 1 Vpr localization: nuclear transport of a viral protein modulated by a putative amphipathic helical structure and its relevance to biological activity. J Mol Biol 1998, 278:13-30.

89. Johnston JB, Jiang $Y$, van Marle G, Mayne MB, Ni W, Holden J, McArthur JC, Power C: Lentivirus infection in the brain induces matrix metalloproteinase expression: role of envelope diversity. J Virol 2000, 74:7211-7220

90. Power C, Henry S, Del Bigio MR, Larsen PH, Corbett D, Imai Y, Yong WW, Peeling J: Intracerebral hemorrhage induces macrophage activation and matrix metalloproteinases. Ann Neurol 2003, 53:731-742.

91. Levy DN, Refaeli Y, MacGregor RR, DB W: Serum Vpr regulates productive infection and latency of human immunodeficiency virus type 1. Proc Natl Acad Sci USA 1994, 91:10873-10877.

92. Ruangkittisakul A, Schwarzacher Stephan W, Lucia Secchia, Poon Betty Y, Yonglie Ma, Funk Gregory D, Klaus B: High Sensitivity to NeuromodulatorActivated Signaling Pathways at Physiological $[\mathrm{K}+]$ of Confocally Imaged Respiratory Center Neurons in On-Line-Calibrated Newborn Rat Brainstem Slices. J Neurosci 2006, 26:11870-11880.

93. Silva C, Zhang K, Tsutsui S, Holden JK, Gill MJ, Power C: Growth hormone prevents human immunodeficiency virus-induced neuronal p53 expression. Ann Neurol 2003, 54:605-614.

94. Ungerstedt $U$, Arbuthnott GW: Quantitative recording of rotational behavior in rats after 6-hydroxy-dopamine lesions of the nigrostriatal dopamine system. Brain Res 1970, 24:485-493.

95. Tsutsui S, Schnermann J, Noorbakhsh F, Henry S, Yong VW, Winston BW, Warren K, Power C: A1 adenosine receptor upregulation and activation attenuates neuroinflammation and demyelination in a model of multiple sclerosis. J Neurosci 2004, 24:1521-1529.

doi:10.1186/1742-4690-8-44

Cite this article as: $\mathrm{Na}$ et al:: Interactions between human immunodeficiency virus (HIV)-1 Vpr expression and innate immunity influence neurovirulence. Retrovirology 2011 8:44.

\section{Submit your next manuscript to BioMed Central and take full advantage of:}

- Convenient online submission

- Thorough peer review

- No space constraints or color figure charges

- Immediate publication on acceptance

- Inclusion in PubMed, CAS, Scopus and Google Scholar

- Research which is freely available for redistribution

Submit your manuscript at www.biomedcentral.com/submit
Biomed Central 